\title{
A development of reduction scenarios of the short-lived climate pollutants (SLCPs) for mitigating global warming and environmental problems
}

Teruyuki Nakajima1*, Toshimasa Ohara ${ }^{1}$, Toshihiko Masui ${ }^{1}$, Toshihiko Takemura², Kei Yoshimura ${ }^{3}$, Daisuke Goto ${ }^{1}$, Tatsuya Hanaoka', Syuichi Itahashi', Gakuji Kurata ${ }^{5}$, Jun-ichi Kurokawa ${ }^{6}$, Takashi Maki ${ }^{7}$, Yuji Masutomi ${ }^{1}$, Makiko Nakata ${ }^{8}$, Tomoko Nitta ${ }^{3}$, Xerxes Seposo ${ }^{9}$, Kengo Sudo ${ }^{10,11}$, Chieko Suzuki ${ }^{12}$, Kentaroh Suzuki ${ }^{13}$, Haruo Tsuruta ${ }^{14}$, Kayo Ueda ${ }^{15}$, Shingo Watanabe ${ }^{11}$, Yong Yu ${ }^{16}$, Keiya Yumimoto ${ }^{2}$ and Shuyun Zhao ${ }^{17}$

\begin{abstract}
This study presents the results of the ERTDF S-12 project for searching an optimum reduction scenario of the shortlived climate pollutants (SLCPS) to simultaneously mitigate the global warming and environmental problems. The study utilized REAS emission inventory, Asia-Pacific Integrated Model-Enduse (AIM/Enduse), MIROC6 climate model, NICAM non-hydrostatic atmospheric model, and models for estimating environmental damages to health, agriculture, and flood risks. Results of various scenario search indicate that it is difficult to attain simultaneous reduction of global warming and environmental damages, unless a significant reduction of $\mathrm{CO}_{2}$ is combined with carefully designed SLCP reductions for $\mathrm{CH}_{4}, \mathrm{SO}_{2}$, black carbon (BC), $\mathrm{NO}_{x}, \mathrm{CO}$, and VOCs. In this scenario design, it is important to take into account the impact of small $\mathrm{BC}$ reduction to the surface air temperature and complex atmospheric chemical interactions such as negative feedback between $\mathrm{CH}_{4}$ and $\mathrm{NO}_{x}$ reduction. We identified two scenarios, i.e., B2a and B1c scenarios which combine the 2D-scenario with SLCP mitigation measures using End-ofPipe (EOP) and new mitigation technologies, as promising to simultaneously mitigate the temperature rise by about $0.33^{\circ} \mathrm{C}$ by 2050 and air pollution in most of the globe for reducing damages in health, agriculture, and flood risk. In Asia and other heavy air pollution areas, health-care measures have to be enhanced in order to suppress the mortality increase due to high temperature in hot spot areas caused by a significant cut of particulate matter. For this situation, the B1b scenario is better to reduce hot spot areas and high-temperature damage to the public health.
\end{abstract}

Keywords: Short-lived climate pollutants, Global warming, Mitigation scenario, Climate change, Air pollution, Environmental problem

\footnotetext{
* Correspondence: terry-nkj@nifty.com

'National Institute for Environmental Studies, 16-2 Onogawa, Tsukuba, Ibaraki 305-8506, Japan

Full list of author information is available at the end of the article
}

\section{Springer Open}

(c) The Author(s). 2020 Open Access This article is licensed under a Creative Commons Attribution 4.0 International License, which permits use, sharing, adaptation, distribution and reproduction in any medium or format, as long as you give appropriate credit to the original author(s) and the source, provide a link to the Creative Commons licence, and indicate if changes were made. The images or other third party material in this article are included in the article's Creative Commons licence, unless indicated otherwise in a credit line to the material. If material is not included in the article's Creative Commons licence and your intended use is not permitted by statutory regulation or exceeds the permitted use, you will need to obtain permission directly from the copyright holder. To view a copy of this licence, visit http://creativecommons.org/licenses/by/4.0/. 


\section{Introduction}

The concept of the short-lived climate pollutants (SLCPs) has been created in the development of global warming mitigation policies to identify anthropogenic atmospheric compositions that produce positive radiative forcing. Black carbon (BC), methane, and tropospheric ozone are key constituents among the SLCPs. UNEP and WMO (2011) proposed a scenario of future global warming mitigation by which a surface air temperature decrease of about $0.5^{\circ} \mathrm{C}$ can be attained by the introduction of SLCP reduction measures along with that of long-lived greenhouse gases (LLGHGs). An international initiative of the Climate and Clean Air Coalition (CCAC) was launched in 2012 with a scope of simultaneous mitigation of global warming and health problem through the reduction of SLCPs and wastes. Such a combined mitigation strategy of LLGHG and SLCP has become more important after the Paris Agreement of COP21 in 2015 set a goal of the global surface air temperature not exceeding $2{ }^{\circ} \mathrm{C}$ and an effort goal of $1.5^{\circ} \mathrm{C}$ relative to the pre-industrial era. According to the IPCC special report on global warming of $1.5^{\circ} \mathrm{C}$ (IPCC 2018), these global warming mitigation goals require a significant reduction of LLGHG emission at a level of almost zero by 2050, which demands the maximum effort of the society. To meet the goals, SLCP reduction is useful to contribute to the mitigation effort, particularly given that a short lifetime of SLCP assures a quick reduction of surface temperature on the order of $0.5^{\circ} \mathrm{C}$ in less than 10 years right after the action of SLCP reduction made. On the other hand, the temperature reduction by LLGHGs takes several 10 years due to their long lifetime in the atmosphere.

The design of effective mitigation measures critically depends on our understanding of the complex climate effects of the short-lived atmospheric compositions including SLCPs and their precursors. This motivated various research efforts in the past taken to challenge the problem, e.g., UNEP ABC project (Ramanathan and Crutzen 2003; Nakajima et al. 2007), AeroCom (Schulz et al. 2006) and AeroCom-II (Myhre et al. 2013), Atmospheric Chemistry and Climate Model Intercomparison Project (ACCMIP) (Shindell et al. 2013), European Union Seventh Framework Programme projectEvaluating the Climate, and Air Quality Impacts of Short-Lived Pollutants (ECLIPSE, Stohl et al. 2015), Asia Pacific Clean Air Partnership (APCAP) (Akimoto et al. 2015; UNEP 2018), NAPEX PDRMIP (Myhre et al. 2017), among others. Ministry of Environment of Japan carried out two SLCP-related strategic researches, i.e., S7 and S-12 by the Environment Research and Technology Development Fund (ERTDF).

This paper summarizes the key results of the S-12 project that aimed at searching an optimum mitigation path of SLCP reduction, conducted in Japanese fiscal years of 2014-2018, through four research theme activities, i.e., (1) analysis of air quality change and development of emission inventories, (2) selection of mitigation technologies and scenario development, (3) investigation of SLCP impacts on the climate and environment, and (4) development for shared tools and a high-resolution atmospheric modeling to link a large variety of scales from regional to global. In this paper, depending on the context, we use the term SLCP to simply identify anthropogenic short-lived atmospheric constituents including scattering aerosols and their precursors as well as absorbing aerosols.

\section{Methods/experimental}

\section{Evaluation of the SLCP effects on the surface air temperature}

One particular issue in designing the effective SLCP reduction scenario is the fact that anthropogenic atmospheric compositions of different species have different signs of the radiative forcing (abbreviated as RF, hereafter). Figure 1 shows direct RFs in China and Asia in a period of 1980-2010 and RF changes caused by 50\% reduction of all the emissions. These are obtained from climate change simulations with the MIROC5/MIROC6 climate models (Watanabe et al. 2010; Tatebe et al. 2019), implemented with SPRINTARS aerosol model (Takemura et al. 2005) and CHASER atmospheric chemistry model (Sudo and Akimoto 2007). The figure indicates that a simple $50 \%$ reduction of the air pollutants produces a net positive forcing of $+10 \mathrm{~mW} \mathrm{~m}^{-2}$ as a result of the cancelation of a negative forcing due to reduction in black carbon $(\mathrm{BC})$, tropospheric ozone $\left(\mathrm{TO}_{3}\right.$, hereafter), and methane $\left(\mathrm{CH}_{4}\right)$ by a positive forcing due to sulfate reduction, suggesting that a simple $50 \%$ reduction is not an optimal scenario to simultaneously mitigate the global warming and air pollution problem.

Another difficulty that complicates the scenario design is the presence of indirect effects between SLCPs and the climate system. Several key indirect effects have been identified in the past studies regarding sulfate, $\mathrm{BC}$, and methane. Figure 2 shows contributions of methane and $\mathrm{TO}_{3}$ to the net RFs as functions of emission change factors of nitrogen oxides $\left(\mathrm{NO}_{x}\right)$, carbon monoxide $(\mathrm{CO})$, and volatile organic compounds (VOCs) including indirect RFs caused by feedbacks among atmospheric compositions. Reference concentrations for the emission factor were assumed to be the 2008 values of the HTAP2 multi-model study (Stjern et al. 2016). The figure indicates that a decrease in $\mathrm{NO}_{x}$ emission produces a negative RF caused by indirect reduction of $\mathrm{TO}_{3}$ and a positive RF due to indirect change of methane, resulting in a net positive RF that acts to warm the globe. This enhanced methane increase is caused by a prolonged 


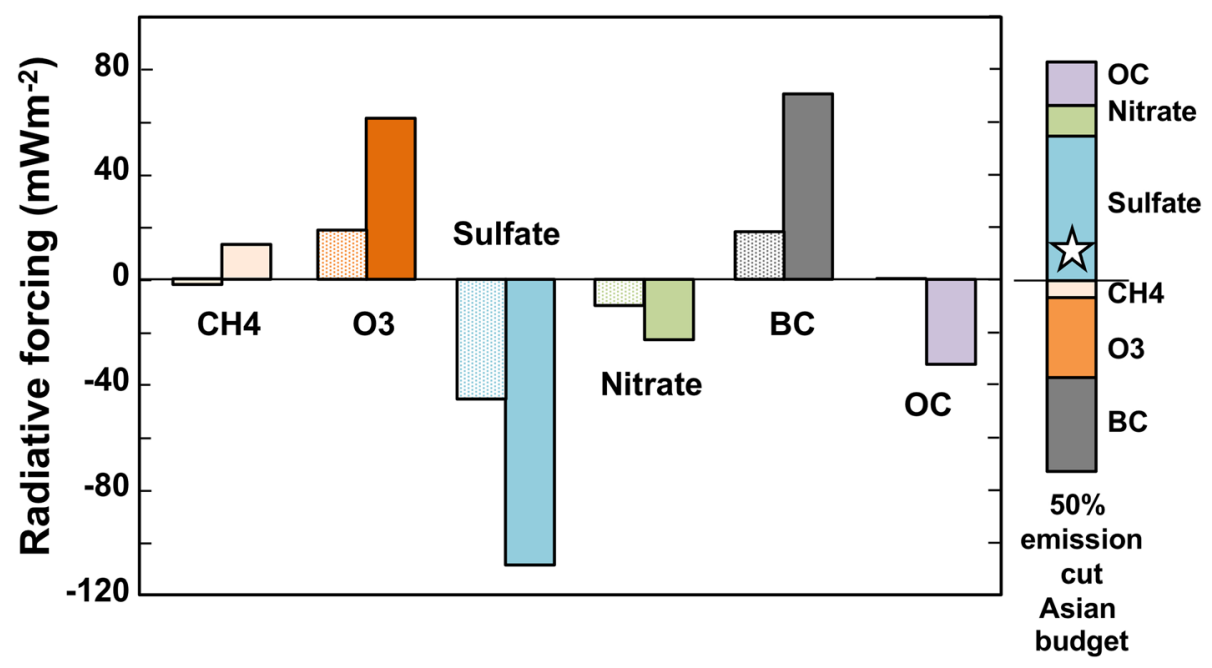

Fig. 1 Instantaneous direct RFs of SLCP emissions in the period of 1980-2010 in Asia (solid right bars) and China (dotted left bars). The Asian budget of RFs caused by $50 \%$ cut of the emissions is also shown aside to the box with a star symbol to show the net total RF

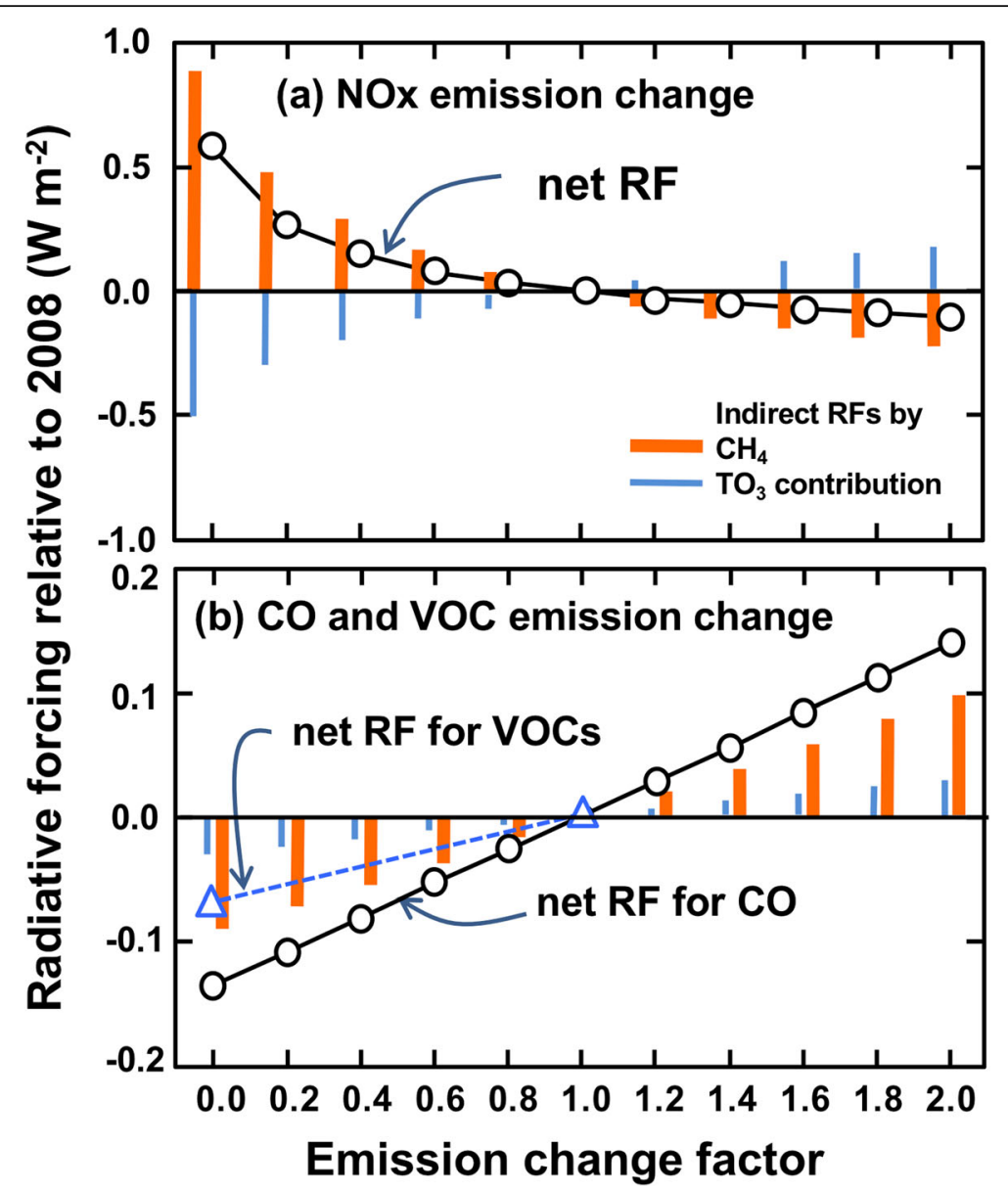

Fig. 2 RF responses to emission change of $\mathbf{a} \mathrm{NO}_{x}$ and $\mathbf{b} \mathrm{CO}$ and $\mathrm{VOC}$. Solid and broken lines show net RF of all the atmospheric constituents, and thick and thin bars show the contributions from methane and $\mathrm{TO}_{3}$, respectively. The reference emission is assumed to be that in 2008 of the HTAP2 scenario 
lifetime of methane due to the reduction of $\mathrm{OH}$ radical (Shindell et al. 2009; Akimoto et al. 2015). On the other hand, $\mathrm{CO}$ emission reduction can produce a negative forcing of methane. This experiment suggests that a careful design of reduced rates of $\mathrm{NO}_{x}$ and $\mathrm{CO}$ is required to attain a reduction of $\mathrm{TO}_{3}$ without increasing methane concentration.

Another process of large uncertainty is the indirect climate effects of sulfate and $\mathrm{BC}$ aerosols, which exert a significant impact on the SLCP-induced climate response. Figure 3, cited from Takemura and Suzuki (2019), shows simulated equilibrium global surface air temperature changes as a function of the instantaneous direct RF, $F_{i}$, of sulfate, and $\mathrm{BC}$ applied to the tropopause. The figure indicates that a sulfate reduction generates a significant temperature rise in a manner mostly proportional to the sulfate loading, whereas a $\mathrm{BC}$ reduction produces a much smaller temperature decrease with the sensitivity or the slope far smaller than that of sulfate. The large climate sensitivity of sulfate is considered to result from the superposition of direct RF and indirect RF due to induced cloud RF of same signs, whereas the small climate sensitivity of $\mathrm{BC}$ is caused by the cancelation of direct RF by indirect RF as also found by previous studies (Hansen et al. 2005; Hodnebrog et al. 2014; Stohl et al. 2015; Samset et al. 2016). Tables 1 and 2 and Fig. 4 compare the values of reported RFs and associated surface air temperature changes caused by $\mathrm{CO}_{2}$ and SLCPs. Here, following Hansen et al. (2005), we define the instantaneous direct RF as the earth radiation budget perturbation at tropopause for RF computation, or simply referred to as the Top Of the Atmosphere (TOA), that occurs immediately when a climate change factor is added to the system, and the effective RF (ERF), $F_{e}$, is defined as the net radiation imbalance with the Sea Surface Temperature (SST) fixed. The latter contains the rapid adjustment of the climate system and is considered to be a direct driver of the slow climate response to cause the global-mean surface air temperature change $\Delta T_{s}$. In this definition, the first and other aerosol indirect effects and semi-direct effects are included in the rapid adjustment. We performed 150-year run for equilibrium climate response using MIROC6 with ocean coupled to estimate $\Delta T_{s}$ and feedback parameter $\beta$ defined as,

$$
F(t) \sim-\beta \Delta T_{s}(t)
$$

where the radiative imbalance at TOA (denoted by $F$ ) and $T_{s}$ are represented to depend on time $(t)$. The $\beta$ value thus defined is known to be similar to that derived from the regression analysis by the method of Gregory (2004) without a large dependence of $\beta$ on the time period of the analysis. We therefore selected the

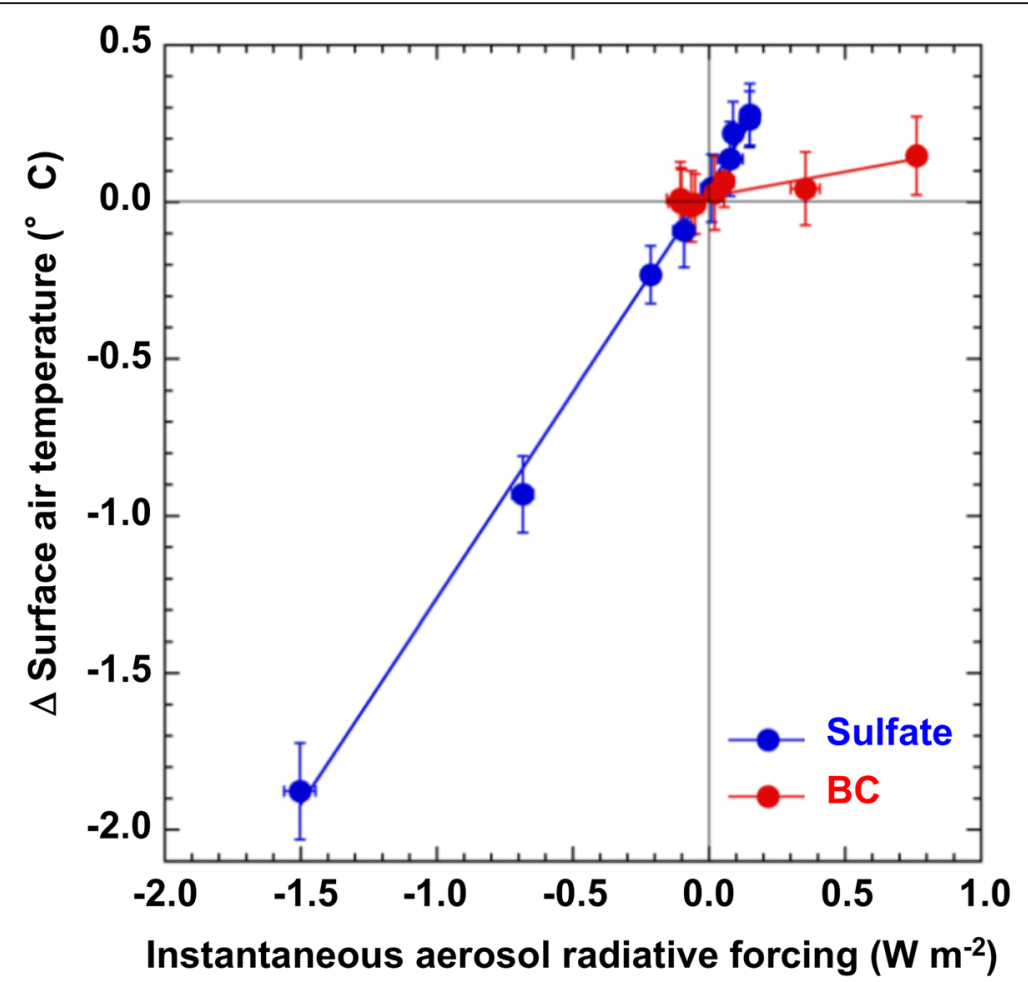

Fig. 3 Relations between instantaneous RFs by sulfate and BC and resulted equilibrium surface air temperature change $\left({ }^{\circ} \mathrm{C}\right)$. Cited from Takemura and Suzuki (2019) 
Table 1 Reported values of instantaneous and effective RFs $\left(\mathrm{Wm}^{-2}\right), F_{i}$ and $F_{e}$, and their ratio $\gamma=F_{e} / F_{i}$

\begin{tabular}{|c|c|c|c|c|c|c|}
\hline${ }^{*} 2 \times \mathrm{CO}_{2}$ & $\mathrm{Fi}$ & Spread & $\mathrm{Fe}$ & Spread & $\gamma=\mathrm{Fe} / \mathrm{Fi}$ & Sources, notes \\
\hline MIROC5 & 4.08 & & 3.68 & & 0.91 & Provided by M. Yoshimori, AORI, University of Tokyo \\
\hline Hansen & 4.52 & & 4.11 & & 0.91 & Hansen et al. (2005) \\
\hline Smith & 2.62 & & 3.7 & & 1.41 & Smith et al. (2018) \\
\hline \multicolumn{7}{|l|}{${ }^{*}$ Aerosols } \\
\hline Shindell-1 & -0.26 & & -1.17 & & 4.50 & Shindell et al. (2013), ACCMIP model \\
\hline IPCC aerosol-2 & -0.42 & \pm 0.24 & -1.92 & \pm 1.0 & 4.57 & IPCC (2013), Fig. 7.19, aeosol RFari (CMIP5) \\
\hline Shindell-2 & -0.39 & & -1.17 & & 3.00 & $\begin{array}{l}\text { Shindell et al. (2013), including missing components } \\
\text { (nitrate and SOA) }\end{array}$ \\
\hline GISS-E2-R & -0.49 & & -1.1 & & 2.24 & Shindell et al. (2013) \\
\hline IPCC aerosol-1 & -0.45 & \pm 0.50 & -0.9 & aci: -0.71 to 0 & 2.00 & IPCC (2013), Figs. TS6 and 7 \\
\hline \multicolumn{7}{|l|}{ *Sulfate } \\
\hline This study & -0.2 & & -0.61 & & 3.02 & Takemura and Suzuki (2019) \\
\hline IPCC sulfate & -0.41 & \pm 0.21 & -0.87 & \pm 0.9 & 2.12 & $\begin{array}{l}\text { IPCC (2013), Fig. TS7 sulfate, 1850-2000; Aci of aerosol; } \\
\text { ari + aci uncertainty of aerosols }\end{array}$ \\
\hline Hansen & -0.63 & & -1.49 & & 2.36 & $\begin{array}{l}\text { Hansen et al. (2005), } 2 \times \text { sulfate; divided by } 2 \text { and added } \\
\text { indirect }\end{array}$ \\
\hline GISS-E2-R & -0.37 & & -0.61 & & 1.65 & Shindell et al. (2013) \\
\hline \multicolumn{7}{|l|}{${ }^{*} \mathrm{BC}$} \\
\hline This study & 0.148 & & 0.008 & & 0.51 & Takemura and Suzuki (2019), Suzuki and Takemura (2019) \\
\hline Hansen & 1.28 & & 0.99 & & 0.77 & Hansen et al. (2005) \\
\hline GISS-E2-R & 0.24 & & 0.46 & & 1.92 & Shindell et al. (2013) \\
\hline Hodnebrog & 0.35 & & 0.09 & & 0.25 & Hodnebrog et al. (2014) \\
\hline NICAM $(\times 10)$ & 0.77 & & 0.32 & & 0.42 & This study, Goto et al. (2020) \\
\hline NICAM (×5) & 0.38 & & 0.14 & & 0.36 & This study, Goto et al. (2020) \\
\hline
\end{tabular}

equilibrium climate sensitivity parameter, $\lambda=1 / \beta$, and the forcing ratio,

$$
\gamma=\frac{F_{e}}{F_{i}}
$$

as useful parameters in our analysis of the SLCP impact for comparison among present and past studies that adopt different methods to evaluate $F_{e}$ with different time scales to separate rapid and slow climate responses.

We compare the reported values of $\gamma$ and $\lambda$ in Fig. 4. Figure $4 \mathrm{a}$ shows that the magnitude of $F_{e}$ for sulfate is $\gamma=1.7$ to 3 times larger than that of $F_{i}$. The $\gamma$ value for the total aerosol is in a range of $\gamma=2$ to 4.5 and is noticeably larger than that for sulfate. This phenomenon can be explained by the fact that the magnitude of $F_{i}$ for the total aerosol is smaller than that for sulfate due to light absorption by absorbing materials externally and internally mixed in the total aerosol. The major contribution to the large $\gamma$ value for sulfate is caused by the first indirect effect of sulfate aerosol acting as effective cloud condensation nuclei $(\mathrm{CCN})$ that enhances lowlevel cloud albedo. On the other hand, the magnitude of $F_{e}$ of $\mathrm{BC}$ is significantly smaller by 25 to $75 \%$ than the magnitude of $F_{i}$ with an exception of GISS-E2-R model which produces a forcing larger than $F_{i}$. Recent studies proposed that the low climate sensitivity of BC occurs as a result of the cancelation of negative $\mathrm{RF}$ due to $\mathrm{BC}$ reduction by a positive RF arising from the cloud system response generated by decreased atmospheric stability due to reduced heating by BC (Stjern et al. 2017; Suzuki and Takemura 2019). There is also a RF due to decreased semi-direct effect associated with decreasing solar radiation absorption by decreased BC. In this regard, it is important to recognize the existence of a large inter-model spread of the ERF induced by $\mathrm{BC}$ and the fact that the MIROC model, used in this study, belongs to the group of small ERF for BC (Shindell et al. 2013). This small $\gamma$ value by the MIROC model is, however, similar to or even larger than the result of $14 \mathrm{~km}$ global simulations by NICAM (Tomita and Satoh 2004; Goto et al. 2020) implemented with more first-principle modeling of cloud formation and aerosol-cloud interaction processes. On the other hand, the $\gamma$ value exceeding the unity in the GISS-ES-R model case also suggests that the $\mathrm{BC}$-induced cloud response might be more complicated to cause cloud forcing that could amplify, rather than dampen, the initial forcing $F_{i}$ (Shindell et al. 2013). 
Table 2 Reported values of $F_{i}, F_{e}$, equilibrium surface air temperature changes $d T_{s}\left({ }^{\circ} \mathrm{C}\right)$, and climate sensitivity, $\lambda=d T_{s} / F_{e}$

\begin{tabular}{|c|c|c|c|c|c|c|}
\hline${ }^{*} 2 \times \mathrm{CO}_{2}$ & $\mathrm{Fi}$ & $\mathrm{Fe}$ & $\Delta T s$ & $\Delta T s / F i$ & $\lambda=\Delta T s / F e$ & Sources, notes \\
\hline MIROC5 & 4.1 & 3.68 & 2.7 & 0.66 & 0.73 & IPCC AR5, fixed SST \\
\hline GISS-E2-R & 2.6 & 2.62 & 2.4 & 0.92 & 0.92 & IPCC AR5, fixed SST \\
\hline IPCC mean & 3.7 & 3.7 & 3.2 & 0.86 & 0.86 & IPCC AR5, fixed SST \\
\hline Hansen & 4.5 & 4.11 & 2 & 0.43 & 0.49 & Hansen et al. (2005) \\
\hline Samset & 3.8 & 3.8 & 2.1 & 0.55 & 0.55 & Smith et al. (2018), Table S2 \\
\hline *Sulfate & & & & 1.31 & & \\
\hline This study & -0.2 & -0.61 & -0.4 & 2.00 & 0.66 & Suzuki and Takemura (2019) \\
\hline Hansen & -0.6 & -1.485 & -1.1 & 1.82 & 0.74 & Hansen et al. (2005), $2 \times$ sulfate; divided by 2 and added indirect \\
\hline Stohl & & -0.86 & -0.7 & & 0.81 & Stohl et al. (2015), model mean of land temperature change \\
\hline Samset & & -3.6 & -2.3 & & 0.64 & Samset et al. (2016) \\
\hline Smith & & -0.7 & -0.5 & & 0.71 & Smith et al. (2018), $5 \times$ sulfate; divided by 5 \\
\hline \multicolumn{7}{|l|}{ *BC } \\
\hline This study & 0.15 & 0.076 & 0.02 & 0.16 & 0.26 & Takemura and Suzuki (2019) \\
\hline Hansen & 1.28 & 0.99 & 0.40 & 0.33 & 0.40 & Hansen et al. (2005), BC \\
\hline Stohl & & 0.33 & 0.05 & & 0.15 & Stohl et al. (2015), model mean of land temperature change, FF + BB, all land emission \\
\hline Myhre & & 0.096 & 0.08 & & 0.83 & Myhre et al. (2017), Stjern et al. (2017), PDRMIP (mean), 10 BC; divided by 10 \\
\hline Smith & & 0.12 & 0.07 & & 0.58 & Smith et al. (2018), 10 BC; divided by 10 \\
\hline
\end{tabular}

(a) $\gamma=F_{e} / F_{i}$

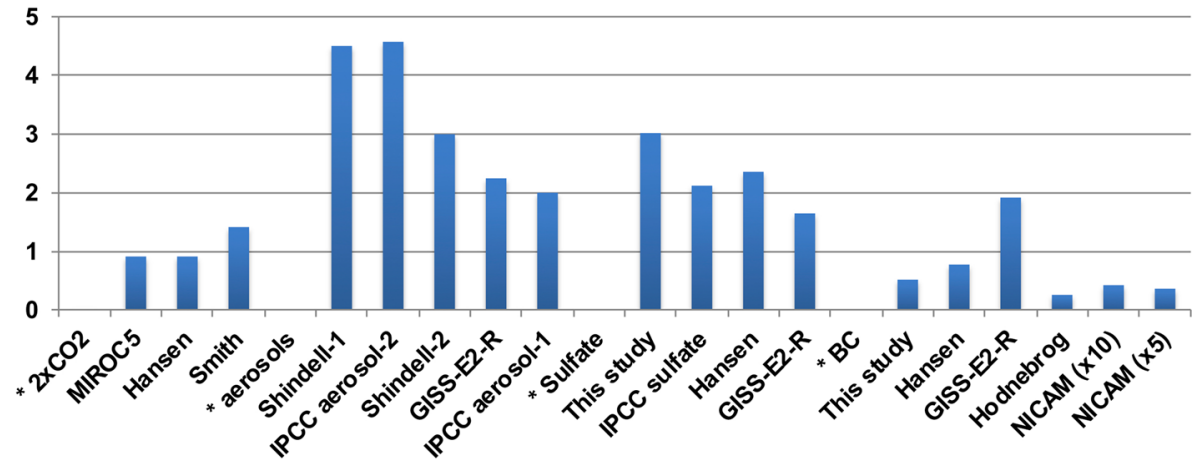

(b) $\lambda=\Delta T_{s} / F_{e}$

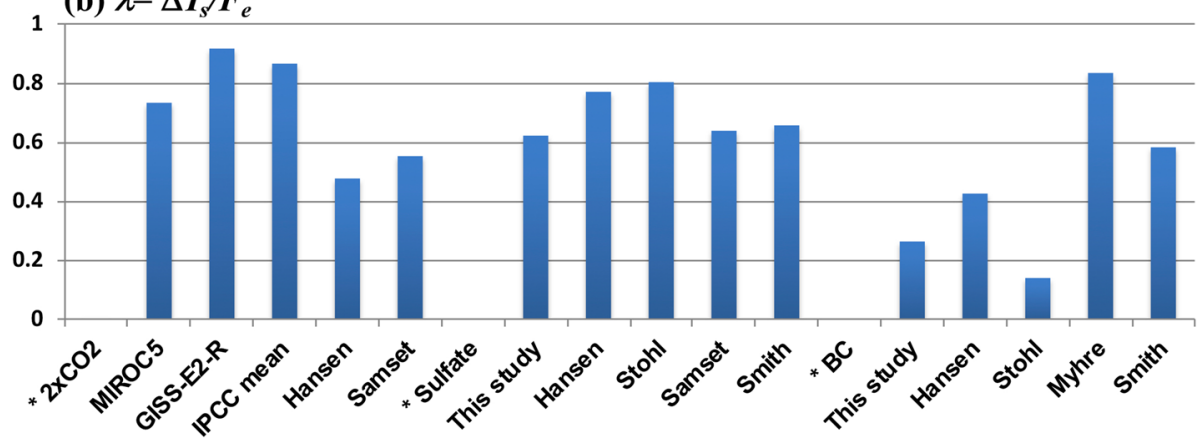

Fig. 4 Reported values of a forcing ratio $\gamma=F_{e} / F_{i}$ and $\mathbf{b}$ climate sensitivity $\lambda=\Delta T / F_{e}$ for $C_{2}$ and SLCPs listed in Tables 1 and 2 
Future studies are needed to conclude this issue, especially in the atmospheric moist convective adjustment process.

Figure $4 \mathrm{~b}$ shows that the $\lambda$ value ranges from 0.6 to 0.8 for sulfate similar to that of doubling $\mathrm{CO}_{2}$ ranging from 0.5 to 0.9 with the model spread smaller for sulfate than for $\mathrm{CO}_{2}$. On the other hand, the slow response to $\mathrm{BC}$ is large model dependent from 0.1 to 0.8 . Although it is early to lead a conclusion before more future model comparisons, the figure suggests that $\mathrm{CO}_{2}$, sulfate and $\mathrm{BC}$ have different effective forcing sensitivities to the slow climate response with different forcing mechanisms, i.e., thermal infrared forcing by $\mathrm{CO}_{2}$, solar forcing to the earth's surface by sulfate, and solar absorption by $\mathrm{BC}$ in the atmosphere. Sulfate causes a unique large cooling of the surface through direct effect and aerosolcloud interaction to increase the cloud optical thickness. MIROC has a large value of the forcing ratio $\gamma$ and small value of $\lambda$, so that the resulted temperature rise per instantaneous forcing is similar to those models with small $\gamma$ and large $\lambda$ values.

There are several issues to improve the large model uncertainties in the RF evaluation used in the model comparisons shown in Fig. 4. A well-known problem is a negative model bias of AOT and a part of which is attributed to the insufficient model treatment of missing nitrate and secondary organic aerosol (Shindell et al. 2013; Shrivastava et al. 2017). Another error source is the inter-model difference in the representation of the mixed state of $\mathrm{BC}$ with other atmospheric compositions (Koch et al. 2009; Oshima and Koike 2013; Matsui et al. 2018) that significantly influences the RF estimate. Also, some of absorption by colored pollution aerosols, such as brown carbon (Kirchstetter et al. 2004) and combustion iron (Moteki et al. 2017), is approximated by BC absorption in a simplified model treatment. The $\mathrm{BC}$ vertical profile is also a key factor affecting the RF and ERF estimates and could be constrained by aircraft measurements through calibrating the wet removal process as claimed by Hodnebrog et al. (2014). Undefined BC sources in the common emission inventories are still a problem, for example, in India (e.g., Goto et al. 2011).

Additional numerical experiments would also be useful to better quantify regional responses to SLCP perturbations, including a shift of the tropical precipitation belt that occurs via both atmosphere and ocean energy transports (Zhao and Suzuki 2019) and modulations of the hydrological cycle over the tropical Asian monsoon regions (Takahashi et al. 2018). High-resolution modeling is also important. Sato et al. (2016) reported an increase in $\mathrm{BC}$ transportation to a polar region with their highresolution modeling, and there is also a recent argument regarding the anti-Twomy response of low clouds as revealed by active satellite remote sensing and high- resolution modeling (Michibata et al. 2016; Sato et al. 2018; Sato and Suzuki 2019). These studies suggest that we need high-resolution modeling that better represents the aerosol and cloud processes for more reliable estimates of RF and climate sensitivity due to the aerosolcloud interaction phenomenon in the scenario impact study.

Figure 5 schematically illustrates various SLCP-related processes affecting the global air temperature and environmental problems (water resource, flooding, draught; health and agricultural damage). In the figure, solid and dashed lines respectively represent positive and negative interactions to produce increasing and decreasing outputs with increasing input. The thickness of the line indicates the strength of the process. As discussed in Figs. 3 and 4, a decrease in sulfate causes an increase in the global surface air temperature by both direct and cloud RF-related indirect effects, but at the same time, it decreases the public health damage, implying a need for a balanced cut of sulfate for reducing the health problem without accelerating the global warming. In contrast, a $\mathrm{BC}$ decrease causes a small net increase in the surface air temperature as a balance of positive direct and negative cloud RF-related indirect effects. It also decreases the environmental problems, so that a substantial cut of $\mathrm{BC}$ is desirable for simultaneous mitigation of global warming and environmental problems. Furthermore, a $\mathrm{NO}_{x}$ decrease causes a decrease in $\mathrm{TO}_{3}$, but at the same time, it causes a negative indirect effect to increase methane as discussed in Fig. 2. In order to weaken the negative effect, we can combine $\mathrm{CO}$ and VOC reductions as a mitigation measure that cancel the $\mathrm{NO}_{x}$ negative feedback and also serve to reduce $\mathrm{TO}_{3}$.

\section{Results and discussion \\ Construction of SLCP scenarios}

The S-12 project adopted the REAS 2.1 emission inventory (Kurokawa et al. 2013) and the Asia-Pacific Integrated Model-Enduse (AIM/Enduse) to relate the mitigation technologies with emissions of SLCPs. Table 3 shows the codes and names of SLCP scenarios constructed by the present project using AIM/Enduse. Details of scenario design are given in Hanaoka and Masui (2020). For this work, the AIM/Enduse has been implemented with several SCLP processes to get a better consistency with the REAS inventory and to output scenario parameters for climate simulations. The reference scenario (Ref-scenario) is a modified version of the SSP2 scenario (O'Neill et al. 2015), in which the future mitigation policies and technologies are taken place with the current trends. The medium and maximum End-of-Pipe (A1 and A2 scenarios) scenarios are scenarios of enhancing EoP-diffusion both in developed and developing countries by 2050 for reducing $\mathrm{SO}_{2}, \mathrm{NO}_{x}, \mathrm{BC}, \mathrm{OC}$, 


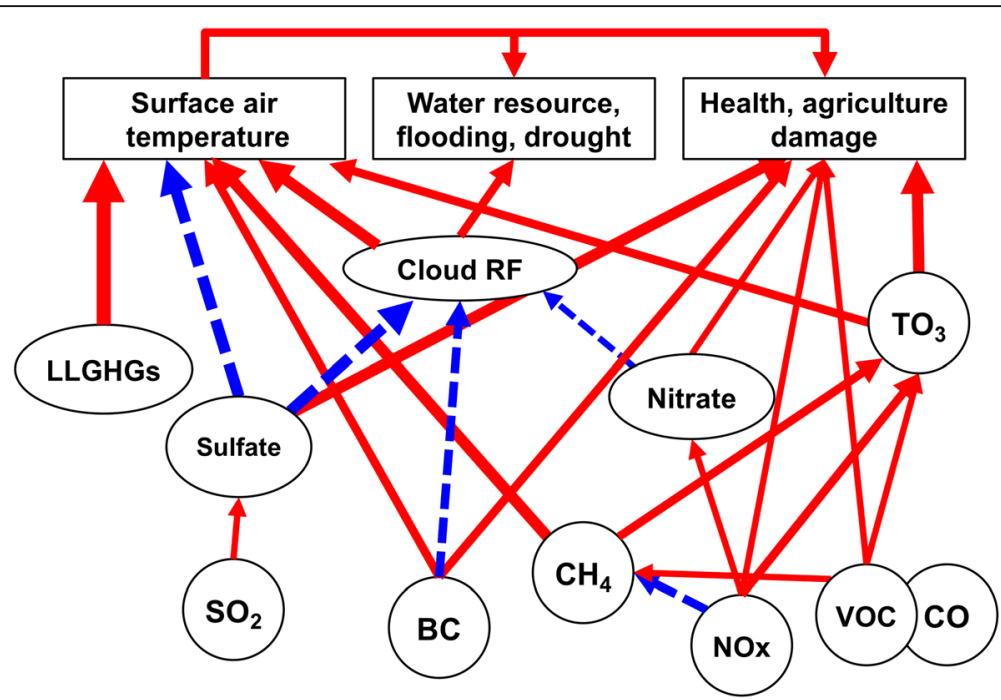

Fig. 5 A diagram to show interactions among processes related with SLCP effects to global surface air temperature and environmental problems (water resource, flooding, draught; health and agricultural damage). Solid and broken lines respectively indicate positive and negative interactions to produce increasing and decreasing outputs with increasing input. Thickness of line illustrates the strength of the effect

PM2.5, and PM10. The 2D-scenario is designed for significant emission reductions of $\mathrm{CO}_{2}$ and methane, by utilizing decarbonization mitigation measures toward the $2{ }^{\circ} \mathrm{C}$ target of the Paris Agreement with reaching a carbon price at $400 \mathrm{US} \$ / \mathrm{tCO}_{2}$ in 2050. The CCSscenario is one of $2 \mathrm{D}$-scenarios with energy shift to coal and biomass power and CCS technology rather than using renewable energies. RES- and BLD-scenarios are 2D-scenarios with energy shift to renewables and with enhancing electrification in the building sector across the world, respectively. The TRT-scenario is for enhancing EV in the passenger transport sector across the world by 2050 . We mainly use the abbreviated scenario codes in this paper, rather than full scenario names, for concise presentation.
Resulted time series of global emissions from 2010 to 2050 are shown in Fig. 6 and their relations in Fig. 7 between (a) $\mathrm{CO}_{2}-\mathrm{SO}_{2}$, (b) $\mathrm{BC}-\mathrm{SO}_{2}$, (c) $\mathrm{CO}-\mathrm{NO}_{x}$, and (d) VOC- $\mathrm{NO}_{x}$. An appendix also presents global spatial distributions of SLCP emission changes. First of all, we note that the simulated emissions at 2010 by the improved AIM model are consistent with those of EDGAR4.3 and HTAP without large gaps in the current condition at 2010. Secondly, Fig. 6 shows that Ref, A2, and A1 scenarios result in $43 \%$ increase of $\mathrm{CO}_{2}$ emission and $53 \%$ increase in methane emission from 2010 to 2050. On the other hand, the introduction of 2D-scenarios reduces $\mathrm{CO}_{2}$ emission by $50 \%$ and methane emission by $44 \%$ from 2010 to 2050. SLCP emission changes depend on how new mitigation technologies are selected among

Table 3 SLCP reduction scenarios developed by the S-12 project

\begin{tabular}{|c|c|c|c|c|c|c|c|}
\hline \multirow[t]{2}{*}{ Scenario group } & \multirow{2}{*}{$\begin{array}{l}\text { Scenario code/ } \\
\text { scenario name }\end{array}$} & \multicolumn{6}{|c|}{ Major combinations of mitigation measures on GHGs, air pollutants, and SLCPS } \\
\hline & & $\begin{array}{l}\text { Enhancement } \\
\text { of end-of-pipe } \\
\text { technology (EoP) }\end{array}$ & $\begin{array}{l}2^{\circ} \mathrm{C} \text { target } \\
\text { measures } \\
(2 \mathrm{D})\end{array}$ & $\begin{array}{l}\text { Enhancement of } \\
\text { carbon capture } \\
\text { and storage (CCS) }\end{array}$ & $\begin{array}{l}\text { Enhancement of } \\
\text { renewable energy } \\
\text { (RES) }\end{array}$ & $\begin{array}{l}\text { Intensive } \\
\text { electrification in } \\
\text { building (BLD) }\end{array}$ & $\begin{array}{l}\text { Intensive } \\
\text { electrification } \\
\text { transport (TRT) }\end{array}$ \\
\hline Reference & Ref/SSP2-based reference & & & & & & \\
\hline \multirow{2}{*}{$\begin{array}{l}\text { End-of-pipe } \\
\text { only }\end{array}$} & A1/EoPmid & Mid & & & & & \\
\hline & A2/EoPmax & Max & & & & & \\
\hline \multirow{6}{*}{$\begin{array}{l}2^{\circ} \mathrm{C} \text { target and } \\
\text { end-of-pipe }\end{array}$} & B1a/2D-EoPmid-CCSBLD & Mid & $\checkmark$ & $\checkmark$ & & $\checkmark$ & \\
\hline & B2a/2D-EoPmax-CCSBLD & Max & $\checkmark$ & $\checkmark$ & & $\checkmark$ & \\
\hline & B1b/2D-EoPmid-RESTRT & Mid & $\checkmark$ & & $\checkmark$ & & $\checkmark$ \\
\hline & B2b/2D-EoPmax-RESTRT & Max & $\checkmark$ & & $\checkmark$ & & $\checkmark$ \\
\hline & $\begin{array}{l}\text { B1C/2D-EoPmid- } \\
\text { RESBLDTRT }\end{array}$ & Mid & $\checkmark$ & & $\checkmark$ & $\checkmark$ & $\checkmark$ \\
\hline & $\begin{array}{l}\text { B2C/2D-EoPmax- } \\
\text { RESBLDTRT }\end{array}$ & Max & $\checkmark$ & & $\checkmark$ & $\checkmark$ & $\checkmark$ \\
\hline
\end{tabular}




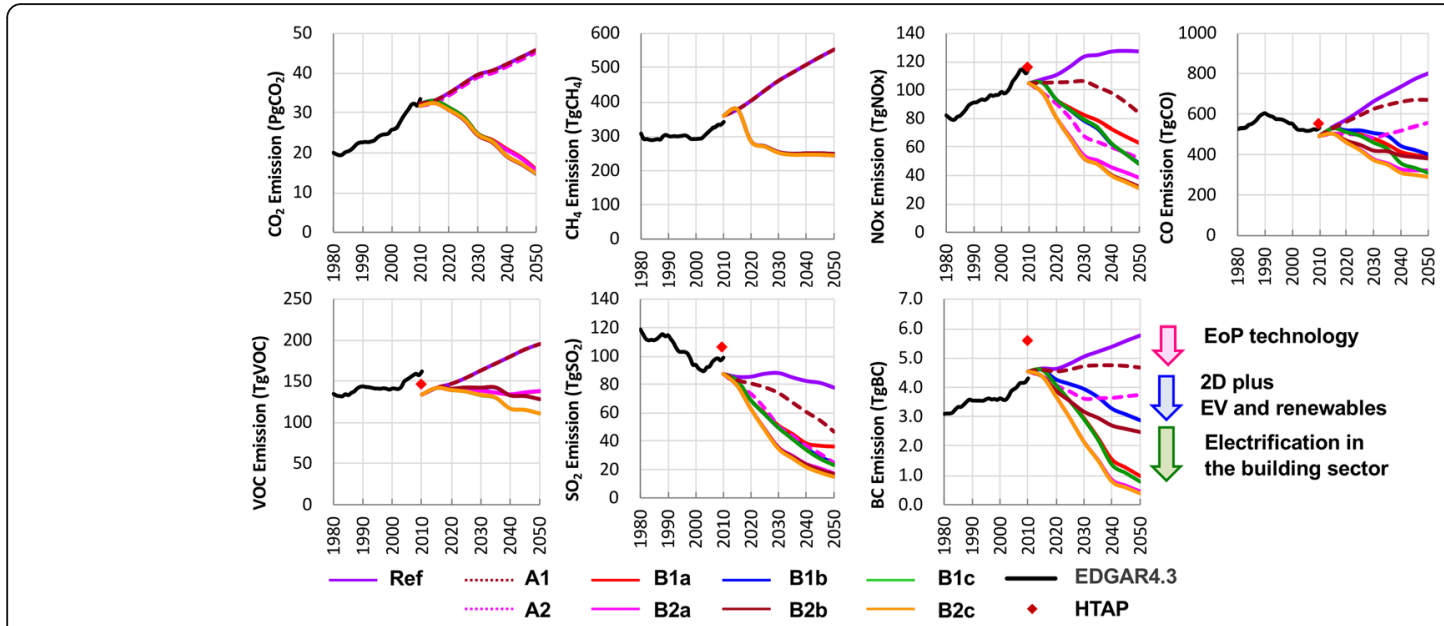

Fig. 6 Time series of global $\mathrm{CO}_{2}$ and SLCP emissions simulated with the scenarios listed in Table 3 from 2010 to 2050. The values of EDGAR and HTAP databases are also added

CCS, RES, BLD, and TRT technologies. The figures show that the EoP-technology is needed for reducing $\mathrm{SO}_{2}, \mathrm{BC}$, and $\mathrm{NO}_{x}$, and we need technologies of CCS, RES, BLD, and TRT to reduce $\mathrm{CO}$, methane, $\mathrm{BC}$, and VOC. These technologies are especially required for a substantial reduction of $\mathrm{BC}$ emission, which is needed to compensate for the small climate sensitivity of $\mathrm{BC}$ as discussed in the previous section. The figures indicate that the $\mathrm{S}-12$ scenarios cover wide combinations of $\mathrm{SO}_{2}$ and $\mathrm{BC}$ emissions. On the other hand, the methane emission shown in Fig. 6 does not have much variety in the scenarios because the major sources of methane are from agriculture and waste sectors for which we do not pose many options for the new mitigation technologies. Future studies of larger emission cuts are needed to be sought by the innovation of new methane reduction

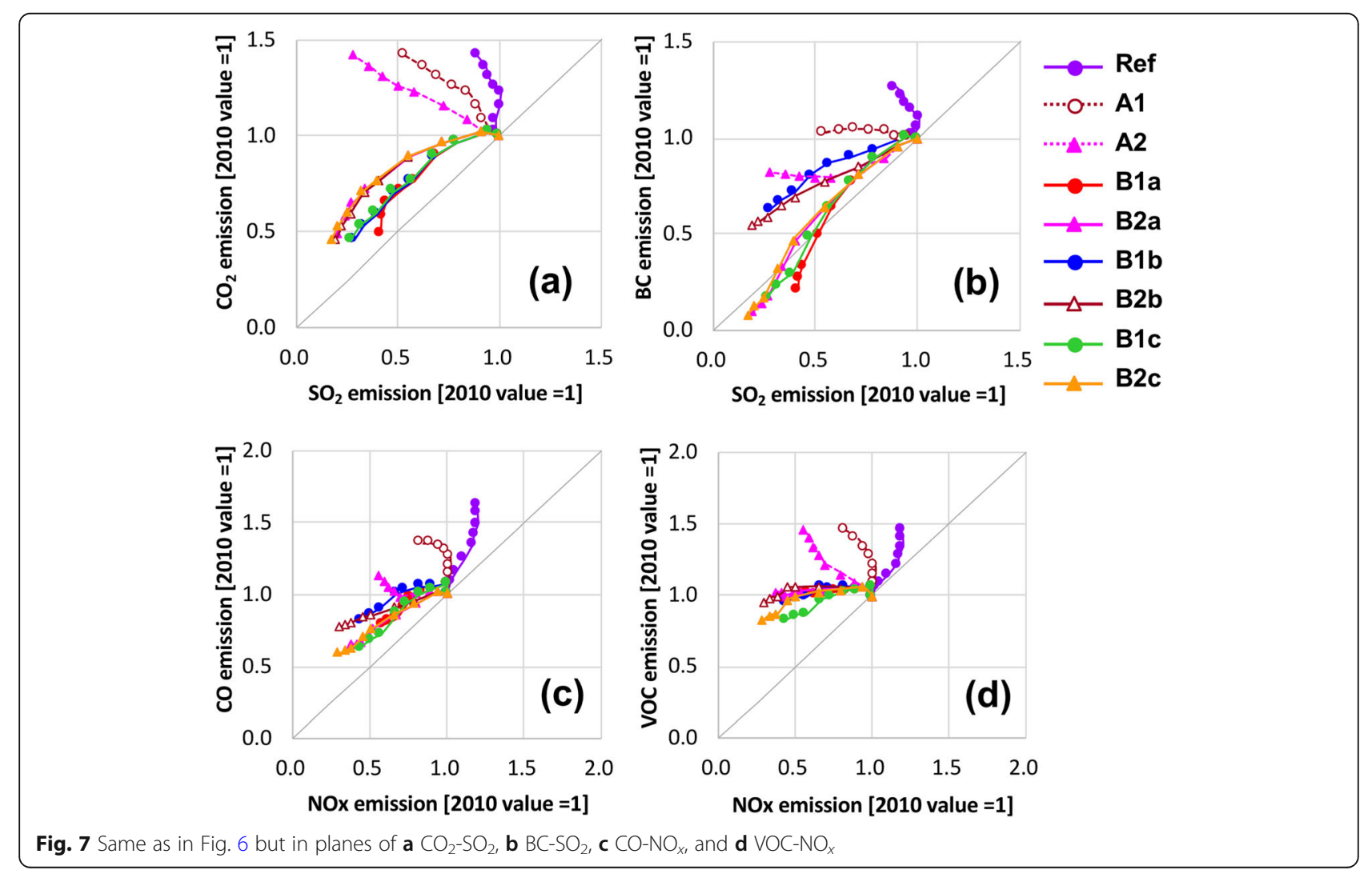


technologies. A study of Fig. 7 for characteristic patterns of relations among SLCP compositions suggest B1a and $\mathrm{B} 1 \mathrm{c}$ scenarios are advantageous for large $\mathrm{BC}$ cut and medium-cut of $\mathrm{SO}_{2}$, while $\mathrm{B} 1 \mathrm{c}$ scenario is useful for a large cut of $\mathrm{CO}$ and $\mathrm{VOC}$ and medium-cut for $\mathrm{NO}_{x}$.

These figures show that there is a large room for bringing different future air compositions by adopting different combinations of the new mitigation technologies. This means that the present study serves as a testbed for the search of the scenarios with results representing a part of the future full search which needs more simulations with climate and environmental models. It is also noted that the cost of introducing new mitigation technologies is larger than that of the EoP technology, that implies a careful discussion considering cost-benefit and trade-offs has to be included in the future scenario search.

Figure 8 shows atmospheric concentrations of $\mathrm{TO}_{3}$ in the Dobson Unit (DU) simulated with the constructed SLCP scenarios. The figure shows that the $\mathrm{TO}_{3}$ concentration will increase in the Ref-scenario with increasing $\mathrm{NO}_{x}$ as indicated in Fig. 6. It is interesting to find that A1 and A2 scenarios increase $\mathrm{TO}_{3}$ even though $\mathrm{NO}_{x}$ is decreased in these scenarios. This phenomenon is understood by increases in $\mathrm{CO}$ and VOC in these scenarios as shown in Fig. 6. Scenarios of new mitigation technologies are successful to reduce $\mathrm{TO}_{3}$, especially by 2.6 DU from 2010s to 2040s with B2a and B1c scenarios. This situation is similar to the indirect effect to the methane concentration as shown in Fig. 9. The methane emission is prescribed in the S-12 scenarios as given in Fig. 6, but the atmospheric concentration of methane is strongly affected by the indirect effect of SLCP compositions as discussed in the preceding section. Dotted lines in Fig. 9 indicate that the methane concentration will increase by $0.2 \mathrm{ppmV}$ for the Ref-scenario more than simulated without the feedback process as presented by solid lines. We found more increase of methane by 0.3 ppmV for A2 scenario caused by a large decrease in $\mathrm{OH}$ radical with decreasing $\mathrm{NO}_{x}$ in the scenario. On the other hand, the figure shows that the reduction of $\mathrm{CO}$ and $\mathrm{VOC}$ in the new technology scenarios successfully suppresses the methane increase due to $\mathrm{NO}_{x}$ reduction.

Figure 10 shows simulated aerosol optical thickness (AOT) and PM2.5 in the globe and East Asia $\left(20^{\circ} \mathrm{N}-\right.$ $\left.50^{\circ} \mathrm{N}, 100^{\circ} \mathrm{E}-150^{\circ} \mathrm{E}\right)$. The figure indicates that the $\mathrm{A} 1$ scenario does not improve AOT and PM2.5, but the A2 scenario can reduce AOT by 0.01 and PM2.5 by $0.3 \mu \mathrm{g}$ $\mathrm{m}^{-3}$ in the globe from the current state. It is important to find that the B1c scenario can perform good mitigation similar to B2a, i.e., AOT by 0.02 and PM2.5 by $0.9 \mu \mathrm{g} \mathrm{m}^{-3}$ from the current state, even when the A1 scenario is adopted but combined with the new mitigation technologies of RES, BLD, and TRT. The East Asian region is more polluted than the global average, so that the role of EoP technology is more important. The Ref-scenario can maintain the present values of AOT and PM2.5, and A2 scenarios will decrease AOT by 0.14 and PM2.5 by $5.3 \mu \mathrm{g}$ $\mathrm{m}^{-3}$, respectively, from 2010. And the B1c scenario can decrease AOT by 0.17 and PM2.5 by $7.3 \mu \mathrm{g} \mathrm{m}^{-3}$.

The analyses in this section are especially important to study the role of the new mitigation technologies to ease the problem that EoP-scenarios (A1 and A2) is beneficial for improving health problem but increases global warming. One conclusion from Figs. 8, 9, 10 is that a pollution control measure to introduce the maximum EoP-technology alone will not lead us to clean and warming mitigation goals, and therefore, we need to

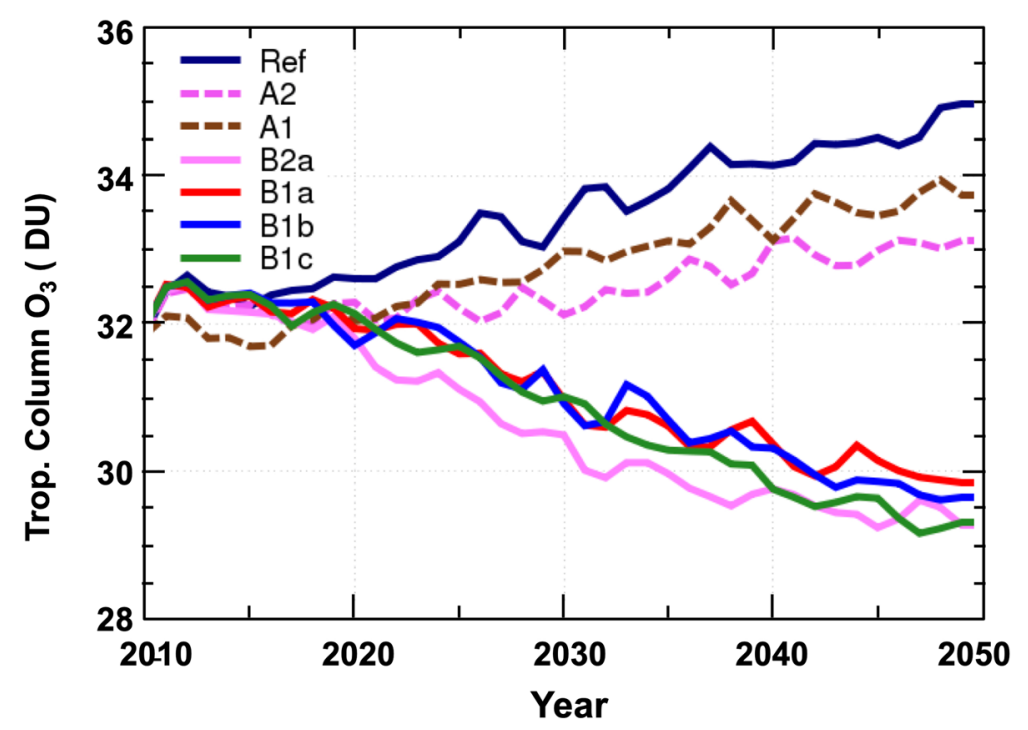

Fig. 8 Time series of global mean $\mathrm{TO}_{3}$ concentrations (DU) simulated with the seven scenarios 


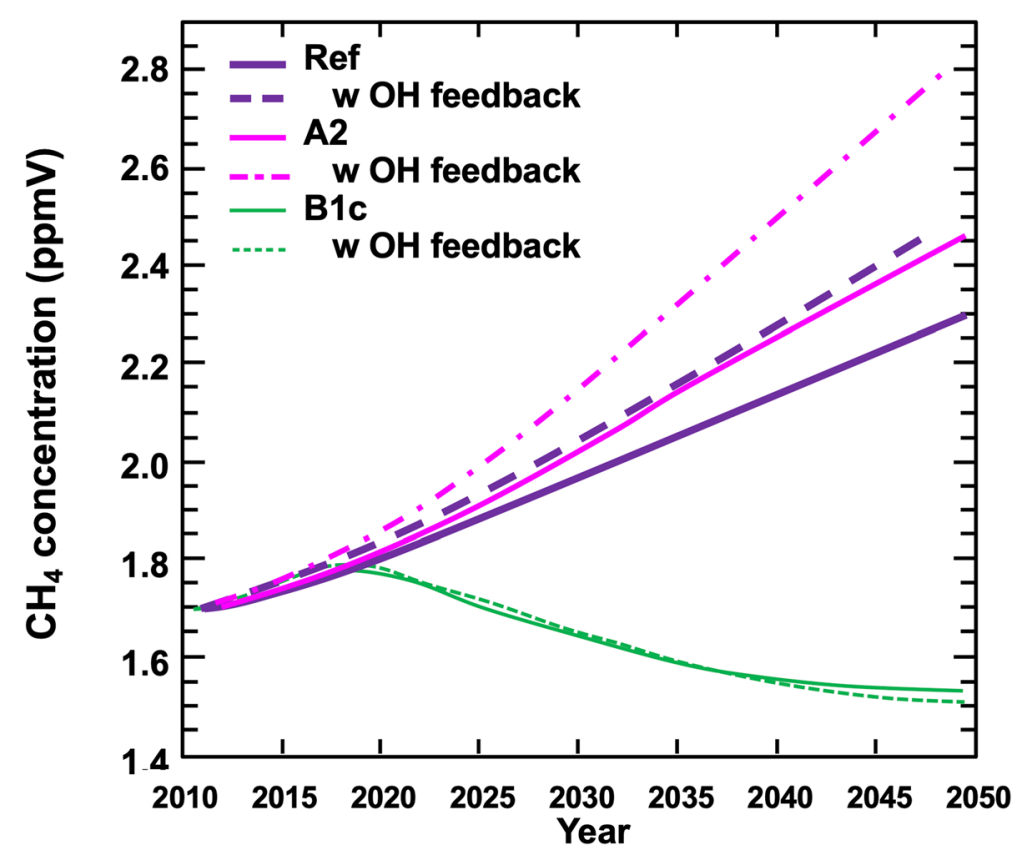

Fig. 9 Time series of global mean methane concentrations (ppmV) simulated with Ref, A2, and B1c scenarios. Dotted lines show simulated concentrations including the indirect effect of $\mathrm{OH}$ radical reactions

combine measures of EoP and new mitigation technologies to attain the goal.

SLCP impacts on the earth's climate and environment Emission scenarios constructed by the AIM/Enduse were used for the MIROC6 climate model to perform seven ensemble runs of coupled atmosphere-ocean model simulation for each scenario with a grid resolution of $1.4^{\circ}$ (T85) for standard simulations and with $0.56^{\circ}$ resolution for high-resolution simulations. In detail, atmospheric concentrations of $\mathrm{CO}_{2}$ and methane were simulated by the MAGICC6 model (Meinshausen et al.

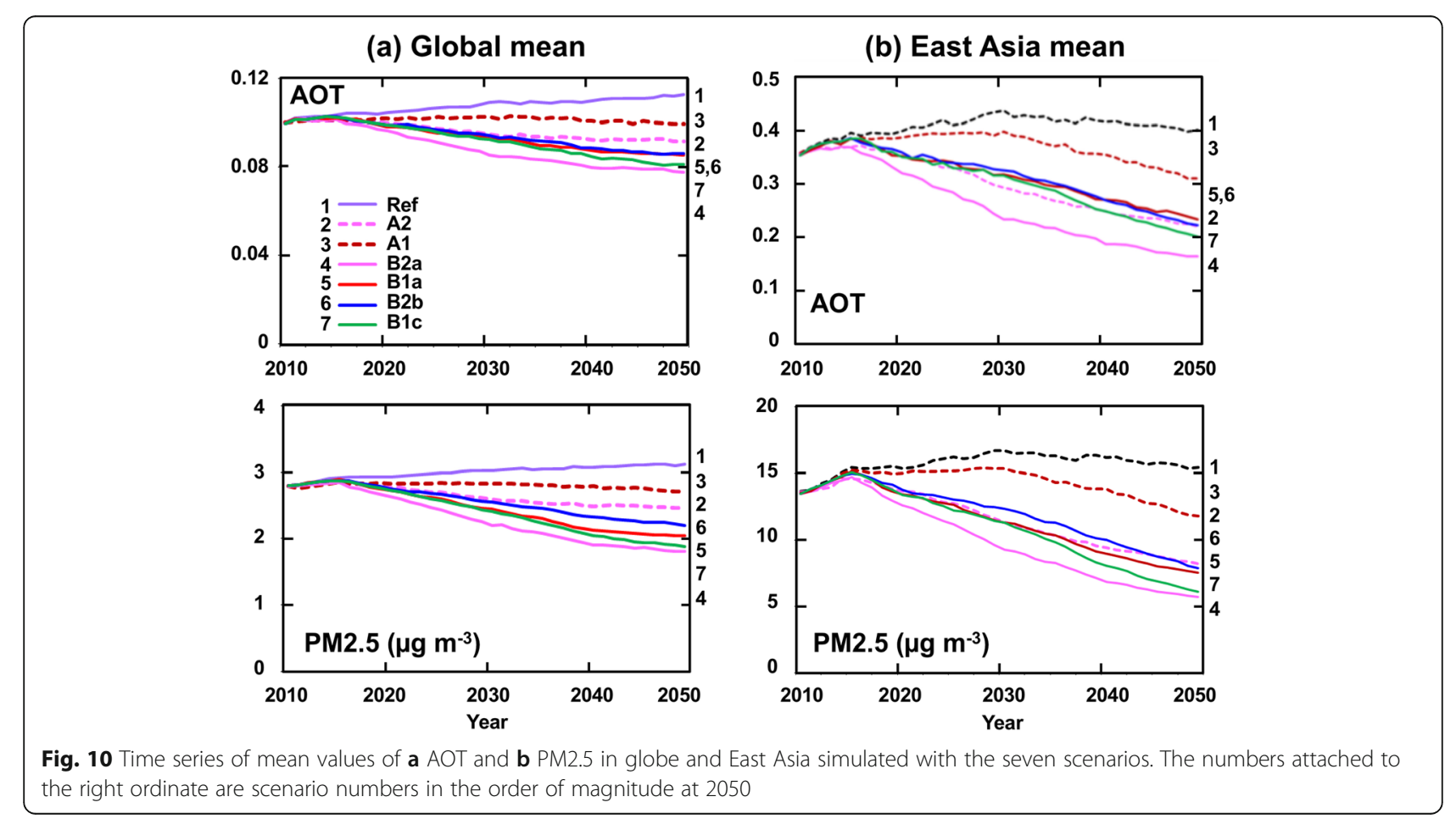


2011) and given to the climate model, while other emissions are directly inputted to the climate model. With this experimental setup, it should be noted that the methane concentration in the climate model is prescribed with AIM/Enduse values depending on the scenario, which neglects the interaction of $\mathrm{CH}_{4}$ and $\mathrm{OH}$ radical or feedbacks from changes in $\mathrm{NO}_{x}, \mathrm{CO}$, and VOCs to alter the methane lifetime.

Figure 11 shows the simulated time series of the global mean surface air temperature changes relative to Refscenario. The figure indicates that Ref-scenario will increase the global mean surface air temperature by about $1.0^{\circ} \mathrm{C}$ by 2050 . The introduction of EoP-technology (A2 and $\mathrm{A} 1$ scenarios) alone increases temperatures more than Ref-scenario about $0.07^{\circ} \mathrm{C}$ with a large positive $\mathrm{RF}$ generated by a decrease of sulfate. This increase will be enhanced if we introduce the indirect effect of methane as discussed in Fig. 9. On the other hand, the introduction of 2D-measures and new mitigation technologies will produce a global mean temperature decrease of about $0.3^{\circ} \mathrm{C}$ from Ref-scenario by 2050 . The best scenarios for warming mitigation are $\mathrm{B} 1 \mathrm{a}$ and $\mathrm{B} 1 \mathrm{c}$ which will decrease the temperature by $0.31^{\circ} \mathrm{C}$ and $0.33{ }^{\circ} \mathrm{C}$ by 2050 , respectively. These scenarios select the $\mathrm{A} 1$ scenario with less reduction of sulfate than A2 scenario indicating an effectiveness of a combination of technologies that simultaneously decreases $\mathrm{SO}_{2}, \mathrm{BC}$, methane, $\mathrm{NO}_{x}, \mathrm{CO}$, and VOC in a suitable amount so as not to produce a large warming by sulfate.

Figures 12 presents global distributions of temperature and precipitation changes by $\mathrm{A} 1$ and $\mathrm{B} 1 \mathrm{c}$ scenarios. The figures show that the A1 scenario produces warming of about $0.4{ }^{\circ} \mathrm{C}$ and precipitation change of about $0.8 \mathrm{~mm}$ day $^{-1}$ in wide areas of the globe relative to the situation of Ref-scenario. On the other hand, the B1c scenario produces a temperature decrease less than $0.4^{\circ} \mathrm{C}$ in most of the globe without a large perturbation of precipitation relative to the Ref-scenario. Among the scenarios in Asia as shown in Fig. 13, B1a and B1c scenarios are useful to reduce the surface air temperature by $0.4^{\circ} \mathrm{C}$ in areas
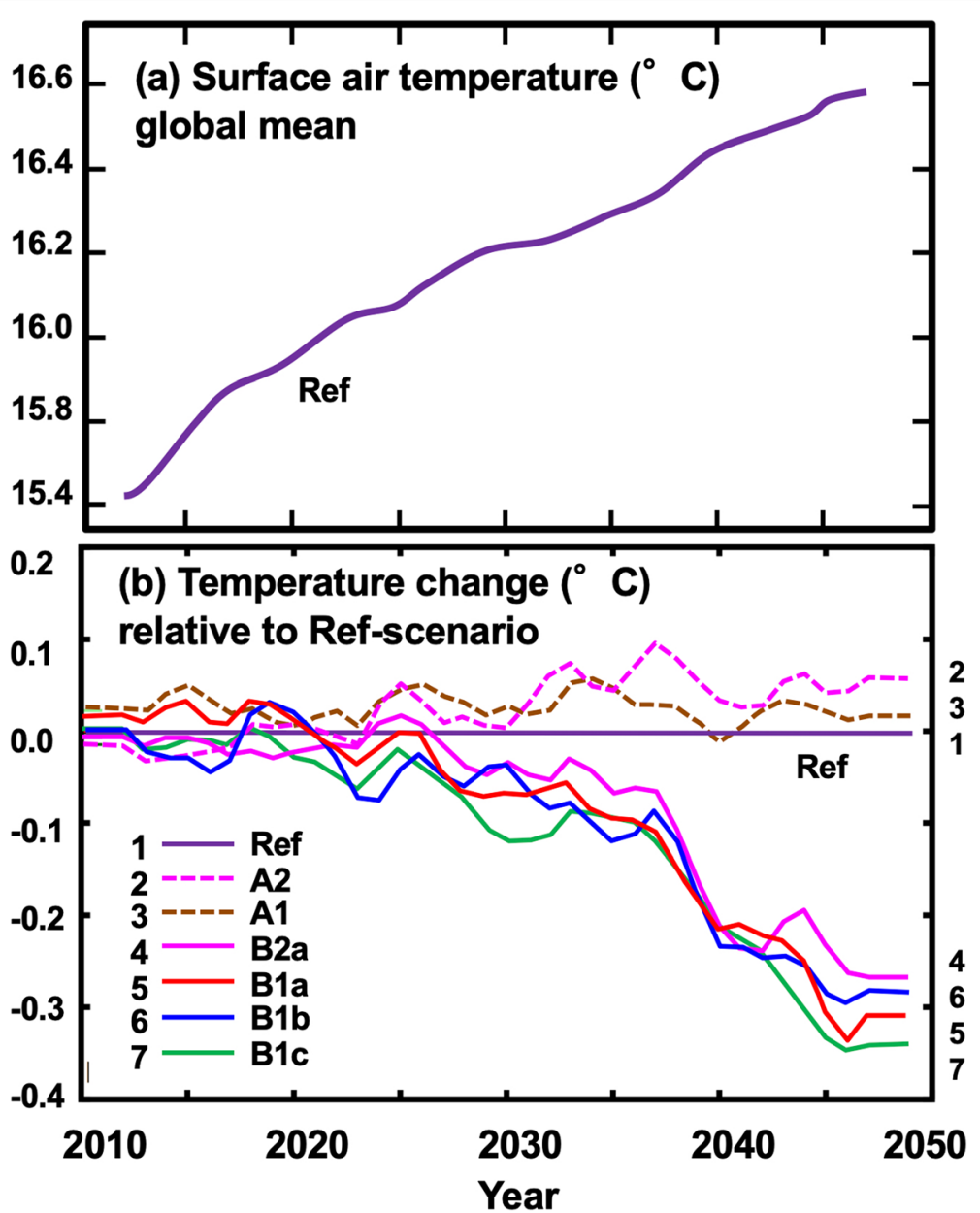

Fig. 11 Time series of a global mean surface air temperature simulated with Ref-scenario and $\mathbf{b}$ temperature changes simulated with the six scenarios relative to Ref-scenario. The numbers attached to the right ordinate are scenario numbers in the order of magnitude at 2050 
other than hot spot areas in India, Myanmar, and China, where the scenarios cannot avoid a temperature increase reaching $0.3^{\circ} \mathrm{C}$ due to a large positive $\mathrm{RF}$ by sulfate reduction.

Figure 14 shows global annual excess mortalities due to PM2.5 and high temperature for Ref2010 and seven scenarios in the 2040s. The excess mortality due to PM2.5 was estimated using the health impact assessment framework of Seposo et al. (2019) as follows:

$$
\begin{aligned}
& \Delta M_{\mathrm{PM} 2.5}=\mathrm{PAF}_{\mathrm{PM} 2.5} \times N, \\
& N=\text { Pop } \times \text { bmort } \\
& \mathrm{PAF}_{\mathrm{PM} 2.5}=\frac{\mathrm{RR}_{\mathrm{PM} 2.5}-1}{\mathrm{RR}_{\mathrm{PM} 2.5}},
\end{aligned}
$$

where $\Delta M_{\mathrm{PM} 2.5}$ is the excess mortality due to PM2.5, a product of population attributable fraction $\left(\mathrm{PAF}_{\mathrm{PM} 2.5}\right)$ and the baseline mortality $(N)$ for each grid; $N$ was calculated by multiplying the population (Pop) by the baseline mortality rate (bmort); $\mathrm{PAF}_{\mathrm{PM} 2.5}$ is the proportion of the mortality that is attributable to PM2.5 and was calculated by using relative risks $\left(R_{\mathrm{PM} 2.5}\right)$,

$$
\begin{aligned}
& \mathrm{RR}_{\mathrm{PM} 2.5}=1+\alpha\left\{1-\exp \left[\left(-\beta\left(Z_{q}-Z_{0}\right)^{\gamma}\right]\right\} \text { if } Z_{q}>Z_{0},\right. \\
& \mathrm{RR}_{\mathrm{PM} 2.5}=1 \quad \text { if } Z_{q} \leq Z_{0},
\end{aligned}
$$

where $Z_{q}$ is the scenario-specific PM2.5 concentration (annual mean) with varying theoretical minima $Z_{0}$ relative to the health outcomes, and an integrated exposureresponse function parameter of $\alpha, \beta, \gamma$ (Burnett et al. 2014). In this study, we estimated RRs for stroke, ischemic heart disease, chronic obstructive pulmonary disease, lung cancer, and acute respiratory infection. We applied the same framework in estimating the excess mortality due to a high temperature. To derive the heatrelated risks $\left(R R_{\text {temp }}\right)$ above the optimum temperature $\left(T_{\text {op }}\right)$, we applied a V-shaped temperature-mortality risk function as,

$$
\begin{aligned}
& \mathrm{RR}_{\text {temp }}=\exp \left\{\delta\left(T_{q}-T_{o p}\right)\right\}, \text { if } T_{q}>T_{o p}, \\
& \mathrm{RR}_{\text {temp }}=1, \text { if } \mathrm{T}_{q} \leq T_{o p},
\end{aligned}
$$

where $\delta$ is the parameter of the risk function above $T_{\mathrm{op}}$; $T_{q}$ is the scenario-specific daily maximum temperature.

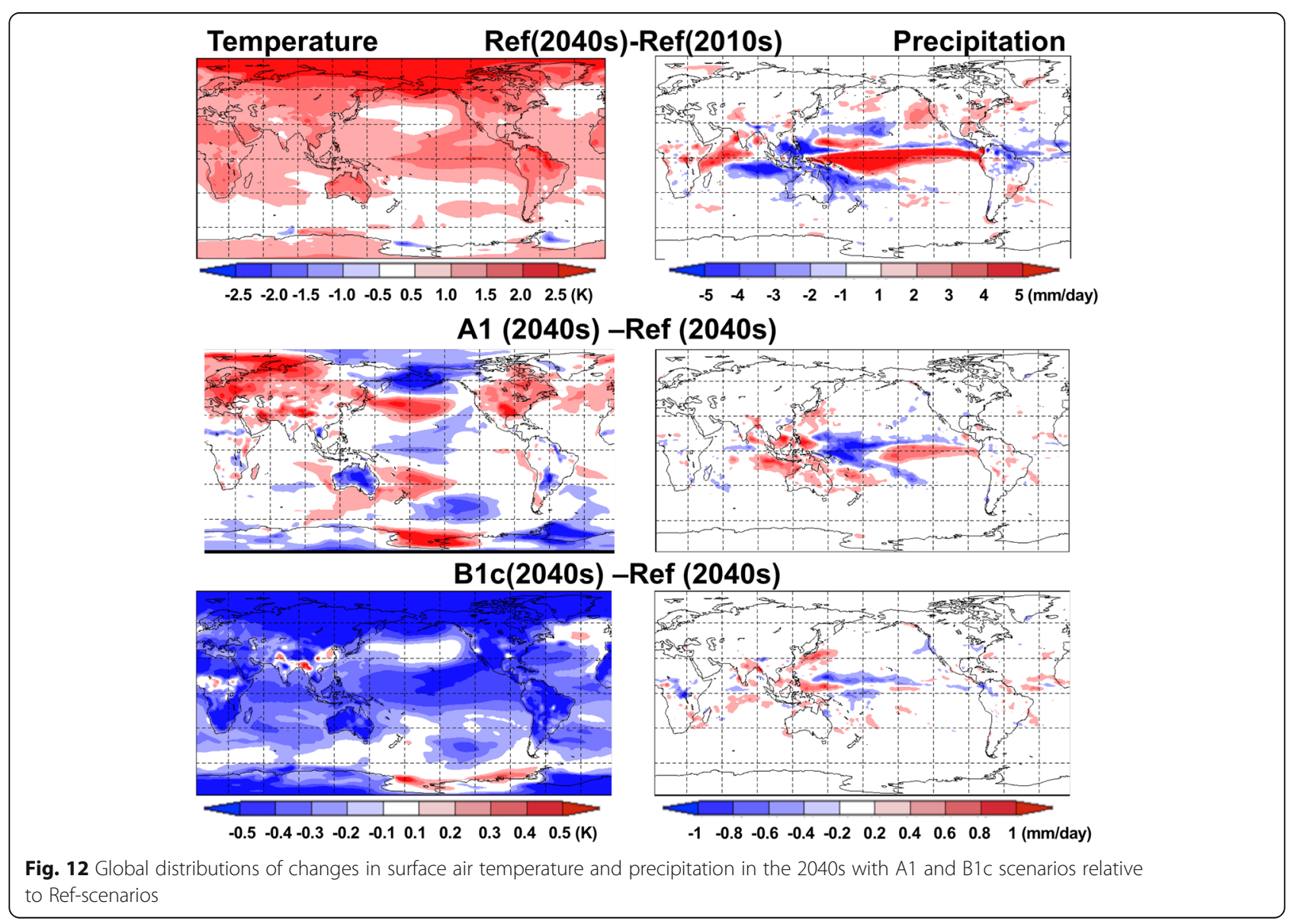




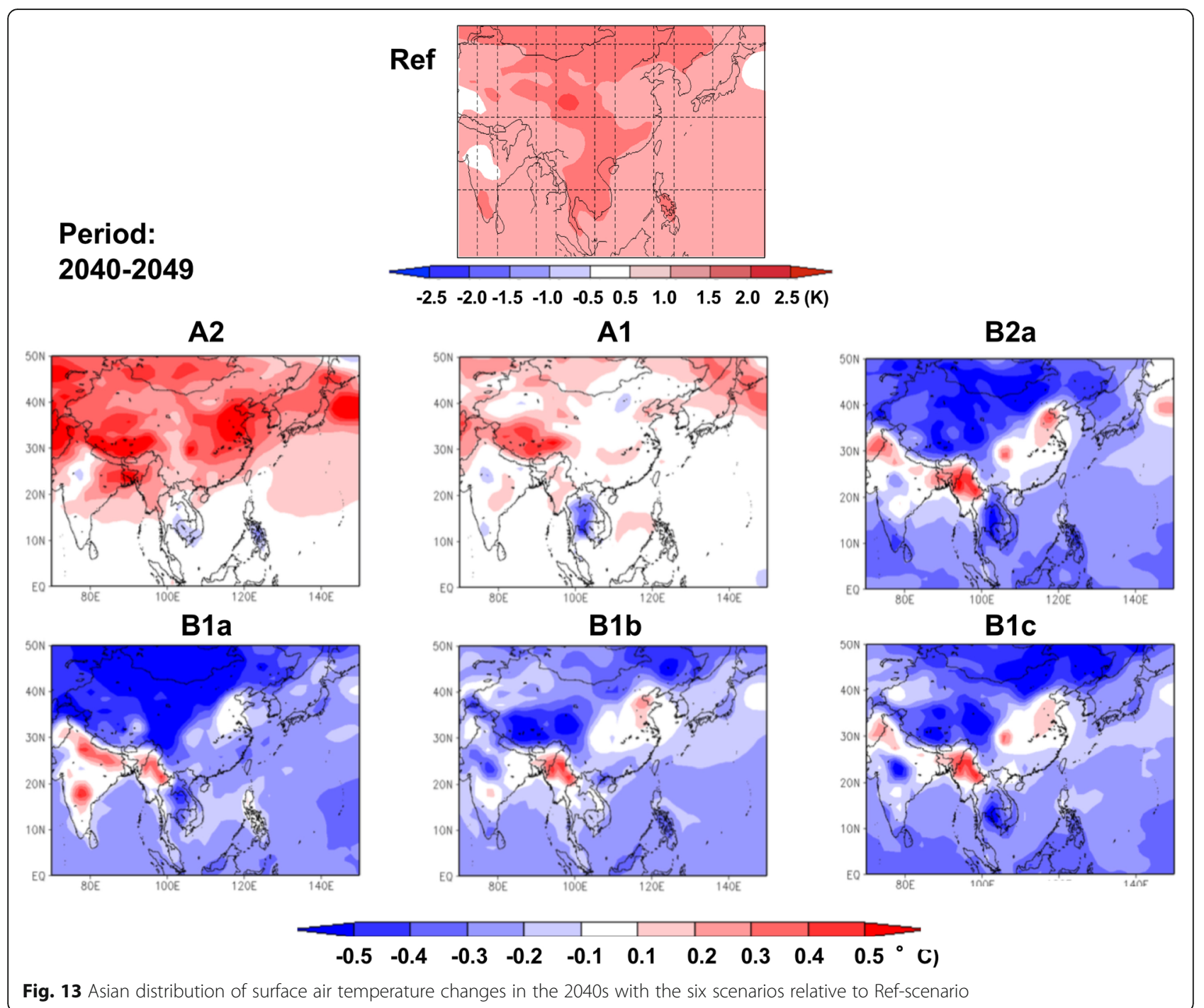

Based on the previous study (Honda et al. 2014), $T_{\mathrm{op}}$ was defined as 84th percentile value of daily maximum temperature for each grid. We summed the daily excess mortalities through the year. We assumed no adaptation measures in the estimation. The figure indicates Ref and A1 scenarios cannot reduce the mortality due to PM2.5 from the situation in the 2010s, because the expected future population increase in polluted areas overcomes the air pollution mitigation effort in these scenarios. We need new mitigation technologies for a substantial decrease in the mortality. The introduction of $\mathrm{B} 2 \mathrm{a}$ and $\mathrm{B} 1 \mathrm{C}$ scenarios will prevent the mortality by 1.2 to 2 million persons per year in the 2040s relative to that of Ref2010. On the other hand, although the magnitude is not as large as that of the PM2.5 impact, the annual mortality due to high temperature will increase from the present with all the scenarios, i.e., 0.022 million persons with B1b scenario to 0.037 million persons with Ref-scenario in the 2040s depending on the global mean temperature rises of $0.6{ }^{\circ} \mathrm{C}$ and $1.0^{\circ} \mathrm{C}$, respectively, as shown in Fig. 11. It is important to note that the mortality also increases in hot spot areas of temperature rise which remain in polluted areas, e.g., India, Myanmar, and China as shown in Fig. 13, caused by a large positive RF by sulfate reduction. This is the reason why $\mathrm{B} 2 \mathrm{a}$ and $\mathrm{B} 1 \mathrm{c}$ scenarios sit next to the $\mathrm{B} 1 \mathrm{~b}$ scenario for mitigation of the mortality, as understood by hot spots higher than those of B1b. An alternative solution of trade-off is to adopt B2a or B1c scenario for mitigation of health damage due to PM2.5 with enhanced anti-high temperature health care in the heavy air pollution areas in Asia where are expected to experience a hot spot-type temperature increase due to significant cut of particulate matter.

Figure 15 presents changes in the rice production due to climate change and ozone estimated by a crop growth simulation model, MATCRO (Masutomi et al. 2016a, 2016b), and a flux-based model for ozone damage on rice (Mills et al. 2018). Annual losses of the rice yield 


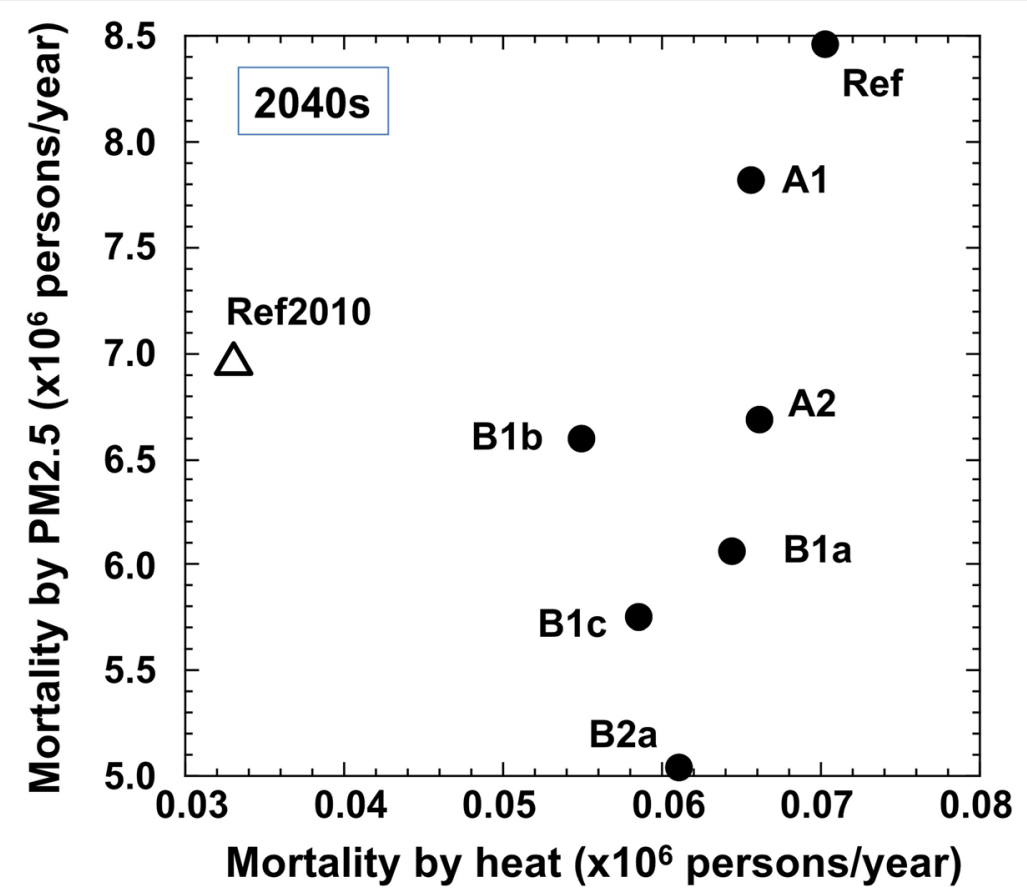

Fig. 14 Global excess mortalities (million persons) due to PM2.5 (ordinate) and high temperature (abscissa) for Ref2010 and seven scenarios in the 2040 s

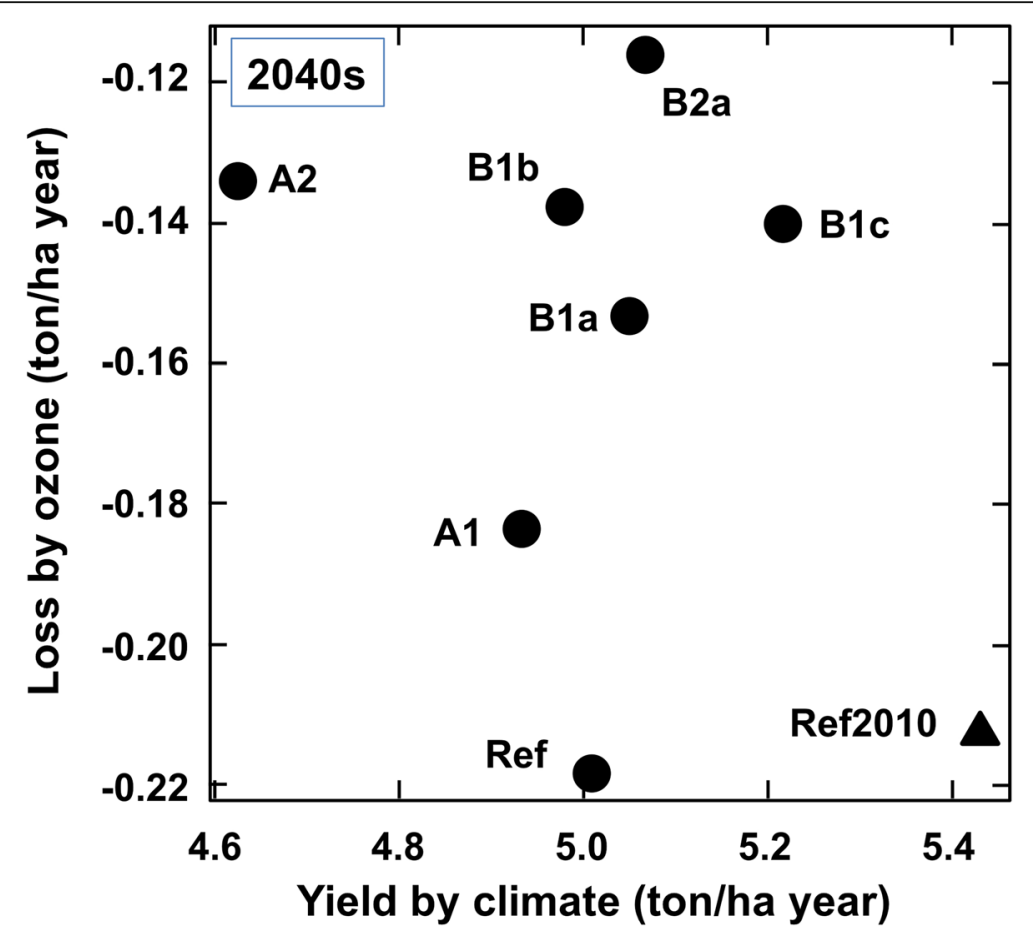

Fig. 15 The same as in Fig. 14 but for global loss of the rice yield by ozone effect (ordinate) and the rice yield by climate other than the ozone effect (abscissa) 
with increasing ozone amount with Ref and A1 scenarios are found in the figure. The loss decreases from the current state (Ref2010) when we introduce EoP technology and new mitigation technologies by 0.10 ton ha ${ }^{-1}$ with B2a and 0.07 ton $\mathrm{ha}^{-1}$ with B1b and B1c scenarios. On the other hand, the climate change decreases the rice production by 0.21 ton $\mathrm{ha}^{-1}$ to 0.80 ton $\mathrm{ha}^{-1}$ with all the scenarios depending on the temperature rise. Different from the case of health impact due to high temperature, however, the least production loss is realized by $\mathrm{B} 2 \mathrm{a}$ and $\mathrm{B} 1 \mathrm{C}$, not $\mathrm{B} 1 \mathrm{~b}$, because the rice production is less affected by the hot spot in the polluted areas.

Figure 16 shows the global population change under risk of flooding and precipitation change when $\mathrm{BC}$ and $\mathrm{SO}_{2}$ concentration change from 0.5 to 10 times less or more than present (Yoshimura et al. 2018). Though the SLCP impacts on globally averaged land precipitation are rather straightforward as decreasing with increasing sulfate or $\mathrm{BC}$, the impact on peak river discharge (i.e., flooding) is not simple because of various impact factors regarding hydrological processes over land including runoff, evaporation, snowmelt, river routing, etc. The figure indicates a V-shaped dependence of the risk with a minimum around the present state, suggesting that the human society has been adapted so as to minimize the disaster risk in the present climate condition. This result indicates the disaster prevention measures in the decreasing global mean precipitation should also be aware of. Although the magnitude of $\mathrm{BC}$ is small and noisy, we found that there is an increasing tendency of flood damage, partly because the precipitation increases in some parts of the land area.

\section{Conclusions}

Figure 17 summarizes changes of $\mathrm{CO}_{2}$, SLCPs, PM2.5, $\mathrm{AOT}$, and environmental parameters relative to Refscenario in the 2040s. The present study concludes that it is possible to create a $\mathrm{CO}_{2}$ and SLCP reduction scenario that simultaneously mitigates global warming and damages on health, agriculture, and water risk by a welldesigned combination of various mitigation technologies as discussed in Figs. 12, 13, 14, 15, and 16. Among the seven scenarios developed in this study, B2a and B1c scenarios are the best to simultaneously mitigate temperature rise, mortality due to PM2.5, and loss of rice production by ozone and climate change, whereas B1b scenario is the best to mitigate the mortality increase due to high temperature because the scenario eases high temperatures in the hot spots caused by positive RF due to sulfate decrease in the polluted area in Asia.

Figure 18 summarizes changes of ERFs of $\mathrm{CO}_{2}$ and SLCPs relative to the Ref-scenario in the 2040s. The figure indicates that the main contributors are emission cut of $\mathrm{CO}_{2}$ and $\mathrm{CH}_{4}$ by the 2D-scenario producing $\mathrm{RFs}$ of about $-0.87 \mathrm{Wm}-{ }^{2}$. The introduction of the EoPtechnology for air quality control will produce a small positive RFs of about $+0.05 \mathrm{Wm}-{ }^{2}$ and will not help mitigation of the global warming. Furthermore, the introduction of new mitigation technologies of CCS,

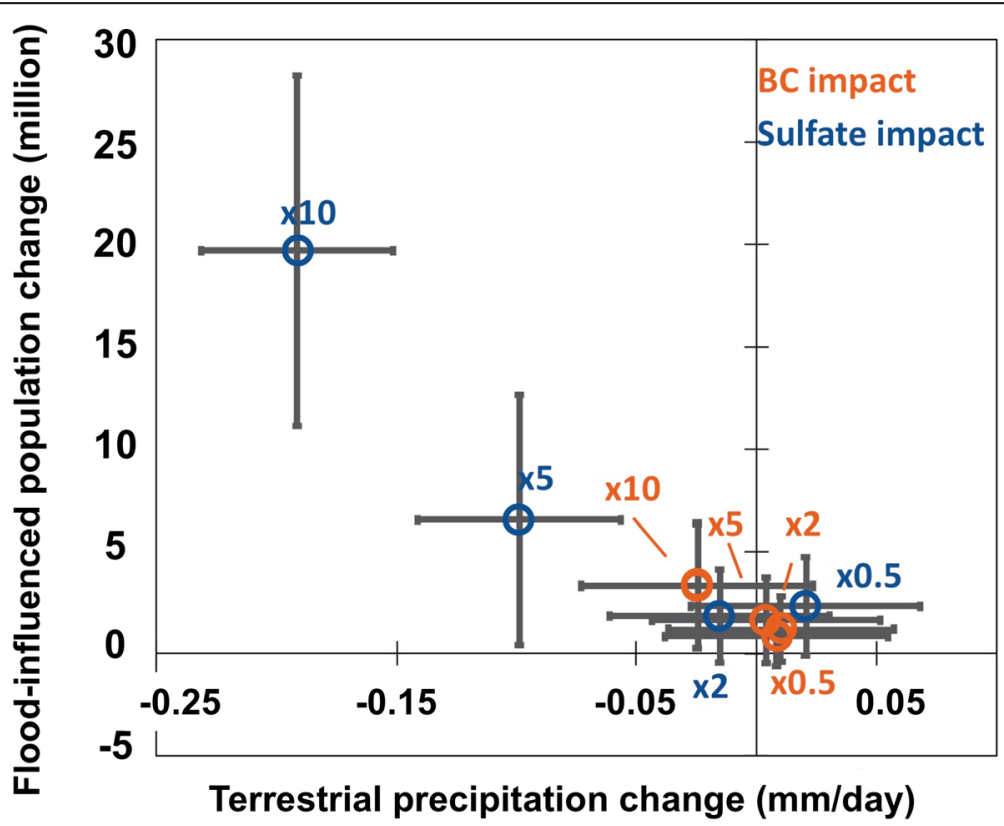

Fig. 16 Relationship between the proportion of the global population exposed to flood risk and changes in terrestrial precipitation due to BC (orange) and sulfate (blue) emissions changes ( 0.5 to 10 times, respectively). Error bars represent the standard deviation of interannual variation during the 20-year simulations 

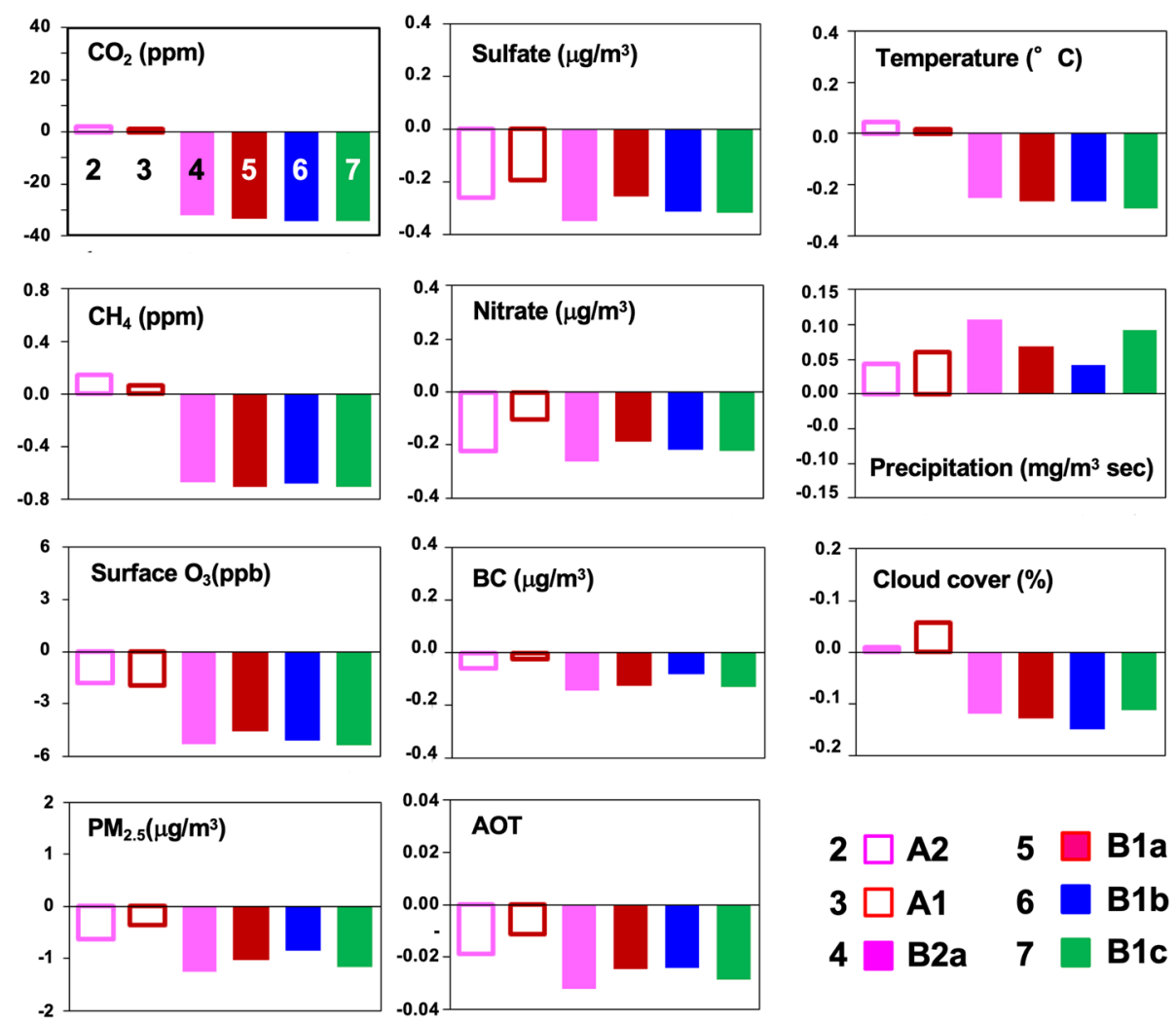

Fig. 17 Changes of global $\mathrm{CO}_{2}$, SLCP concentrations, and environmental parameters in the 2040s with the six scenarios relative to Ref-scenario

RES, BLD, and TRT reduces sulfate for improving air quality more than EoP-scenarios, and it produces positive ERF more than $+1 \mathrm{Wm}^{-2}$. The figure indicates, however, the advantage of the new mitigation technologies is to compensate for the positive sulfate ERF by negative ERFs by $\mathrm{TO}_{3}$ and $\mathrm{BC}$ reductions to result in a larger net reduction of the total ERF about $-1.4 \mathrm{Wm}^{-2}$. The figure indicates the best scenario of reducing the total ERF is the B1c scenario with $-0.7 \mathrm{Wm}^{-2}$ better than that of $\mathrm{B} 2 \mathrm{~b}$. Also, it is important to note that the small value of BC ERF does not mean small climate impacts of BC, because of the reduced amount of ERF from instantaneous RF, $F_{i} / F_{e}$ shown in Fig. $4 \mathrm{a}$, is used to induce changes in the fast component of the climate system including global cloud and precipitation changes (Suzuki and Takemura 2019).

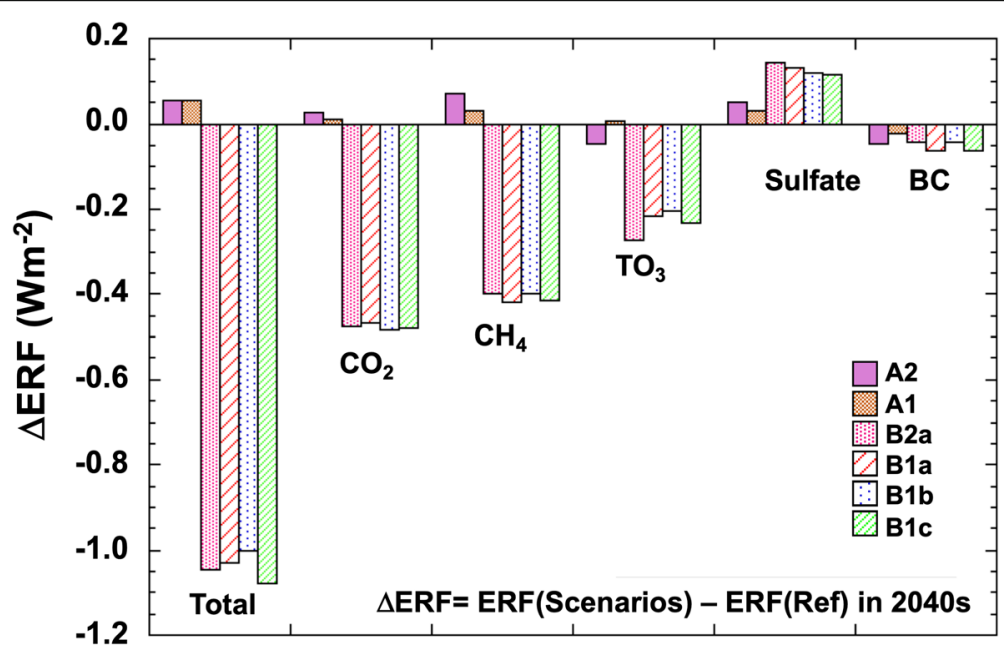

Fig. 18 Changes of ERFs in the 2040s with the six scenarios relative to Ref-scenario 
Although these results suggest recommendable scenarios for simultaneous mitigation of global warming and environmental problems, we feel that the knowledge obtained by the present study is still limited to find the ultimate best scenario, and several undone works are left for future works. First, we should continue the effort of evaluating $\mathrm{BC}$ forcing because estimates of $\gamma$ and $\lambda$ values are largely scattered as shown in Fig. 4. Indirect effects on methane and $\mathrm{TO}_{3}$ are also important processes in the scenario construction, because they increase scenario differences between EoP-scenarios and 2D-scenarios than presented in Figs. 17 and 18. Furthermore, emission change scenarios in Figs. 6 and 7 suggest that there is still a large room for bringing different future air compositions by adopting different combinations of the new mitigation technologies, especially for those of methane. The cost of introducing new mitigation technologies is larger than that of EoP technology, so that a careful discussion considering cost-benefit and the trade-off has to be included in the scenario search.

As found by Fig. 4, large model uncertainties of RFs still exist and can be an Achilles tendon for reliable scenario construction. Future studies are, therefore, needed for improving the model treatment of missing nitrate and secondary organic aerosol, representation of the mixed state of $\mathrm{BC}$, and colored aerosols, $\mathrm{BC}$ vertical profile, and undefined $\mathrm{BC}$ sources in Asia, and other areas. Also, future detailed ensemble simulations with coupled atmosphere-ocean models and multi-model experiments are needed to investigate the $\mathrm{BC}$ impact in the situation of large model dependency as described in Section 2. Such additional experiments would also be useful to better quantify regional responses to SLCP perturbations.
Another important challenge for the effective SLCP mitigation is to cycle the scenario construction and their assessment by monitoring the air quality and climate state. One of significant problems met in the S-12 project is the long turnaround time of emission inventory construction by the bottom-up method based on various census data, which became a bottleneck in the project for understanding the emission gap between emission inventories and constructed scenarios. In order to ease this problem, we introduced $\mathrm{NO}_{x}$ emissions in the Asian region retrieved from the satellite data (Yumimoto et al. 2015). Fig. 19 compares estimates of the annual $\mathrm{NO}_{x}$ emission from the Chinese area using updated versions of REAS 2.2 and satellite retrieval (Kurokawa et al. 2017; Itahashi et al. 2019). The figure shows the emission inventory significantly exceeds the satellite-based estimate by about 2 Mton/year after 2011. We found the difference is caused by problems both in the inventory and the satellite methods. As for the bottom-up emission inventory REAS, introduction rates of denitrification equipment to large power plants were underestimated. On the other hand, the rapid increase in Chinese emissions caused negative biases in the satellite values. To overcome this problem, we developed a sequential update technique (Itahashi et al. 2019). The revised inventory and satellite values get closer to each other as illustrated in Fig. 19. This update helped reducing the gap between REAS emission and AIM/Enduse scenario in Asia as reported by Hanaoka and Masui (2020). This experience clearly indicates shortening the turn-around time of the scenario construction and air quality monitoring cycle is useful to healthy SLCP mitigation measures along with the global stock-take initiatives by UNFCCC.

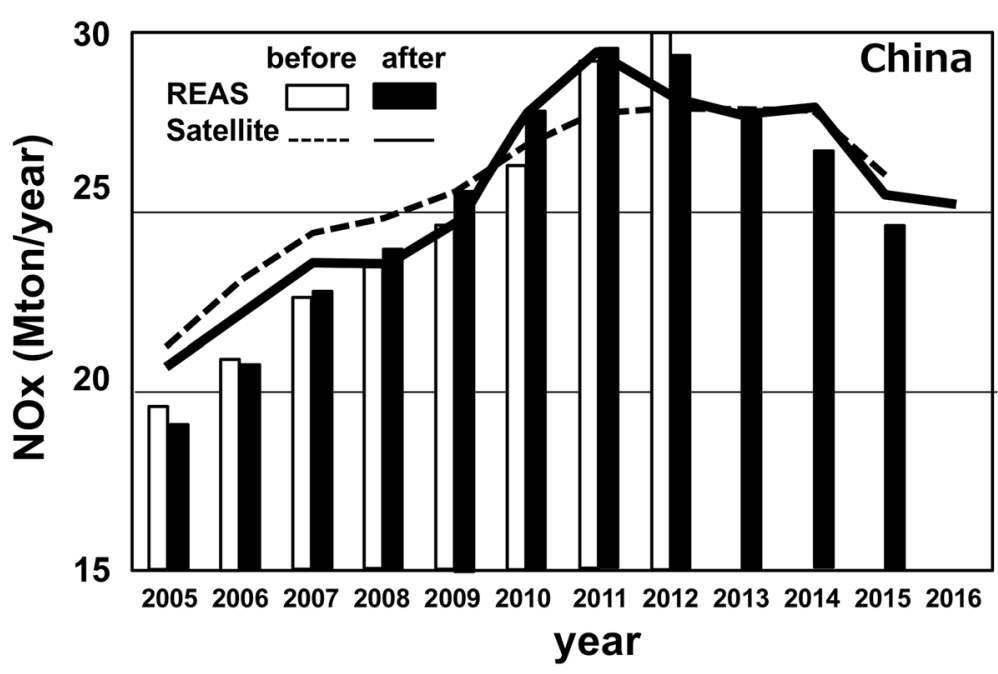

Fig. 19 Estimates of the annual $\mathrm{NO}_{x}$ emission from Chinese area using REAS emission inventories and satellite retrievals. Dashed line and open bars show the original values before improvements of REAS and satellite algorithm, and solid line and closed bars are for after improvements 


\section{Supplementary information}

Supplementary information accompanies this paper at https://doi.org/10. 1186/s40645-020-00351-1.

Additional file 1: Figure A1 shows global spatial distributions of SLCP emissions in the 2010s (2010-2019) with the Ref-scenario (Ref2010) and emission changes with the seven scenarios in the 2040s (2040-2049) relative to Ref2010. It is found from the figure that the reduction rates of SLCP compositions depend on regions, so that large regional differences in the mixing state of SLCPs are expected resulting in different magnitudes and signs of RF. BLD- and TRT-technologies are effective to reduce $\mathrm{BC}$ and $\mathrm{NO}_{x}$ emissions, especially in Asia, Africa, and South America. Large increase in $\mathrm{NO}_{x}$ in Asia can be eased by combination of CCS-, BLD-, and TRT-technologies. Fig. A1(a). Global distributions of emissions $\left(\mathrm{g} \mathrm{m}^{-2} \mathrm{yr}^{-1}\right)$ with Ref2010 and emission changes in the 2040s with the seven scenarios relative to Ref2010 for $\mathrm{SO}_{2}$. Fig. A1(b). Same as Fig. A1(a), but for $\mathrm{NO}_{x}$. Fig. $\mathrm{A} 1$ (c). Same as Fig. A1(a), but for BC. Fig. A1(d). Same as Fig. A1(a), but for OC.

\section{Abbreviations}

AIM: Asia-Pacific Integrated Model; CHASER: Chemical AGCM for Study of Atmospheric Environment and Radiative Forcing; BC: Black carbon; AOT: Aerosol optical thickness; CO: Carbon monoxide; ERF: Effective radiative forcing; ERTDF: Environment Research and Technology Development Fund; MIROC: Model for Interdisciplinary Research on Climate; NICA M: Nonhydrostatic ICosahedral Atmospheric Model; OC: Organic carbon; REAS: Regional Emission inventory in ASia; RF: Radiative forcing; SLCP: Shortlived climate pollutants; SPRINTARS: Spectral radiation-transport model for aerosol species; SSP: Shared socioeconomic pathways; TO3: Tropospheric ozone; VOC: Volatile organic compounds

\section{Acknowledgements}

The Japanese information of the $\$ 12$ project is given at http://157.82.240.16 7/ S12/moej-s12/index.html. Model simulations were performed on the supercomputer system of JAXA/JSS2, NIES/NEC SX-ACE, RIKEN/K computer (hp140046, hp150156, hp160004, hp170017, hp180012), JAMSTEC/Earth Simulator, and University of Tokyo/PRIMEHPC FX10.

We express our deep condolence to the passing away of Gakuji Kurata, Kyoto University, who was an active member of the S-12 project.

\section{Authors' contributions}

TN was the principal investigator of the S-12 project. TO, DG, SI, JK, TM, and KY contributed to the analysis of air quality change and development of emission inventories; TM, GK, and TH to the selection of mitigation technologies and scenario development; TT, YM, MN, XS, CS, KS, KU, SW, and $Y Y$ to the investigation of SLCP impacts on the climate and environment; KY, TN, KS, HT, and SZ to development for shared tools and a high resolution atmospheric and hydrologic modeling. The authors read and approved the final manuscript.

\section{Authors' information}

Correspondence and requests for materials should be addressed to TN (terry-nkj@nifty.com).

\section{Funding}

The S-12 (JPMEERF14S11200) was one of the projects in the Strategic Research and Development Area of the Environment Research and Technology Development Fund (ERDF), Environmental Restoration and Conservation Agency (ERCA), Japan. Parts of this research were also supported by projects of JST/CREST/EMS/TEEDDA (JPMJCR15K4), NIES/ GOSAT\&GOSAT-2 projects, and "Integrated Research Program for Advancing Climate Models (TOUGOU)" Grant Number JPMXD0717935457 from the Ministry of Education, Culture, Sports, Science, and Technology (MEXT), Japan.

\section{Availability of data and materials}

The datasets used and analyzed during the current study are available from the corresponding author on reasonable request.

\section{Competing interests}

The authors declare that they have no competing interests.

\section{Author details}

${ }^{1}$ National Institute for Environmental Studies, 16-2 Onogawa, Tsukuba, Ibaraki 305-8506, Japan. ${ }^{2}$ Research Institute for Applied Mechanics, Kyushu University, Fukuoka, Japan. ${ }^{3}$ IIS Chiba Experimental Station, The University of Tokyo, 5-1-5 Kashiwanoha, Kashiwa, Chiba 277-8574, Japan. ${ }^{4}$ Central Research Institute of Electric Power Industry, 1646 Abiko, Chiba 270-1194, Japan. ${ }^{5}$ Department of Environmental Engineering, Graduate School of Engineering, Kyoto University, Katsura, Nishikyo-ku, Kyoto 615-8540, Japan. ${ }^{6}$ Atmospheric Research Department, Asia Center for Air Pollution Research, 1182 Sowa, Nishi-ku, Niigata 950-2144, Japan. ${ }^{7}$ Meteorological Research Institute, Nagamine, Tsukuba, Ibaraki 305-0052, Japan. ${ }^{8}$ Faculty of Sociology Department of Environment, Kindai University, 3-4-1 Kowakae, Higashiosaka 577-8502, Japan. ${ }^{9}$ Nagasaki University School of Tropical Medicine and Global Health, 1-12-4 Sakamoto, Nagasaki 852-8523, Japan. ${ }^{10}$ Graduate School of Environmental Studies, Nagoya University, Nagoya 464-8601, Japan. ${ }^{11}$ Research Institute for Global Change, Japan Agency for Marine-Earth Science and Technology, 3173-25 Showa, Kanazawa-ku, Yokohama 2360001, Japan. ${ }^{12}$ Research Institute for Value-Added-Information Generation, Japan Agency for Marine-Earth Science and Technology, 3173-25 Showa, Kanazawa-ku, Yokohama 236-0001, Japan. ${ }^{13}$ Atmosphere and Ocean Research Institute, The University of Tokyo, 5-1-5 Kashiwanoha, Kashiwa, Chiba 277-8568, Japan. ${ }^{14}$ Remote Sensing Technology Center of Japan, 317-1 Toranomon, Minato-ku, Tokyo 105-0001, Japan. ${ }^{15}$ Graduate School of Global Environmental Studies, Kyoto University, Yoshida-Honmachi, Sakyo-ku, Kyoto 606-8501, Japan. ${ }^{16}$ School of Geographical Science, Nanjing University of Information Science \& Technology, No.219, Ningliu Road, Nanjing, Jiangsu, China. ${ }^{17}$ Department of Atmospheric Science, China University of

Geosciences, No. 388 Lumo Road, Wuhan, China.

Received: 16 February 2020 Accepted: 8 July 2020

Published online: 27 July 2020

\section{References}

Akimoto H, Kurokawa J, Sudo K, Nagashima T, Takemura T, Klimonte Z, Amann M, Suzuki K (2015) SLCP co-control approach in East Asia: tropospheric ozone reduction strategy by simultaneous reduction of NOx/NMVOC and methane. Atmos Environ 122:588-595

Burnett RT, Pope CA 3rd, Ezzati M, Olives C, Lim SS, Mehta S, Shin HH, Singh G, Hubbell B, Brauer M, Anderson HR, Smith KR, Balmes JR, Bruce NG, Kan H, Laden F, Prüss-Ustün A, Turner MC, Gapstur SM, Diver WR, Cohen A (2014) An integrated risk function for estimating the global burden of disease attributable to ambient fine particulate matter exposure. Environ Health Perspect 122:397-403. https://doi.org/10.1289/ehp.1307049

Goto D, Sato Y, Yashiro H, Suzuki K, Oikawa E, Kudo R, Nagao TM, Nakajima T (2020) Global aerosol simulations on a $14-\mathrm{km}$ grid spacing for a climate study: improved and remaining issues relative to a lower-resolution model. Geosci Model Dev in press

Goto D, Takemura T, Nakajima T, Badarinath KVS (2011) Global aerosol modelderived black carbon concentration and single scattering albedo over Indian region and its comparison with ground observations. Atmos Environ 45: 3277-3285. https://doi.org/10.1016/j.atmosenv.2011.03.037

Gregory JM (2004) A new method for diagnosing radiative forcing and climate sensitivity. Geophys Res Lett 31:L03205

Hanaoka T, Masui T (2020) Exploring effective short-lived climate pollutant mitigation scenarios by considering synergies and trade-offs of combinations of air pollutant measures and low carbon measures towards the level of the $2{ }^{\circ} \mathrm{C}$ target in Asia. Environ Pollut. https://doi.org/10.1016/j.envpol.2019.113650

Hansen J, Sato M, Ruedy R, Nazarenko L, Lacis A, Schmidt GA, Russell G, Aleinov I, Bauer M, Bauer S, Bell N, Cairns B, Canuto V, Chandler M, Cheng Y, Del Genio A, Faluvegi G, Fleming E, Friend A, Hall T, Jackman C, Kelley M, Kiang N, Koch D, Lean J, Lerner J, Lo K, Menon S, Miller R, Minnis P, Novakov T, Oinas V, Perlwitz JA, Perlwitz JU, Rind D, Romanou A, Shindell D, Stone P, Sun S, Tausnev N, Thresher D, Wielicki B, Wong T, Yao M, Zhang S (2005) Efficacy of climate forcings. J Geophys Res 110:D18104. https://doi.org/10.1029/ 2005JD005776

Hodnebrog Ø, Myhre G, Samset BH (2014) How shorter black carbon lifetime alters its climate effect. Nature Comm 5:5065. https://doi.org/10.1038/ncomms6065 
Honda Y, Kondo M, McGregor G, Kim H, Guo YL, Hijioka Y, Yoshikawa M, Oka K, Takano S, Hales S, Kovats RS (2014) Heat-related mortality risk model for climate change impact projection. Environ Health Prev Med 19:56-63. https://doi.org/10.1007/s12199-013-0354-6

IPCC (2013) In: Stocker TF, Qin D, Plattner G-K, Tignor M, Allen SK, Boschung J, Nauels A, Xia Y, Bex V, Midgley PM (eds) Climate change 2013: the physical science basis. Contribution of working group I to the fifth assessment report of the intergovernmental panel on climate change. Cambridge University Press, Cambridge and New York, p 1535

IPCC (2018) In: Masson-Delmotte V, Zhai P, Pörtner H-O, Roberts D, Skea J, Shukla PR, Pirani A, Moufouma-Okia W, Péan C, Pidcock R, Connors S, Matthews JBR, Chen Y, Zhou X, Gomis MI, Lonnoy E, Maycock T, Tignor M, Waterfield T (eds) Global warming of $1.5^{\circ} \mathrm{C}$. an IPCC special report on the impacts of global warming of $1.5^{\circ} \mathrm{C}$ above pre-industrial levels and related global greenhouse gas emission pathways, in the context of strengthening the global response to the threat of climate change, sustainable development, and efforts to eradicate poverty

Itahashi S, Yumimoto K, Kurokawa J, Morino Y, Nagashima T, Miyazaki K, Maki T, Ohara T (2019) Inverse estimation of NOx emissions over China and India 2005-2016: contrasting recent trends and future perspectives. Environ Res Lett 14:124020. https://doi.org/10.1088/1748-9326/ab4d7f

Kirchstetter TW, Novakov T, Hobbs PV (2004) Evidence that the spectral dependence of light absorption by aerosols is affected by organic carbon. $J$ Geophys Res 109:D21208. https://doi.org/10.1029/2004JD004999

Koch D, Schulz M, Kinne S, McNaughton C, Spackman JR, Balkanski Y, Bauer S, Berntsen T, Bond TC, Boucher O, Chin M, Clarke A, De Luca N, Dentener F, Diehl T, Dubovik O, Easter R, Farey DW, Feichter J, Fillmore D, Freitag S, Ghan S, Ginoux P, Gong S, Horowitz L, Iversen T, Kirkevåg A, Klimont Z, Kondo Y, Krol M, Liu X, Miller R, Montanaro V, Moteki N, Myhre G, Penner JE, Perlwitz J, Pitari G, Reddy S, Sahu L, Sakamoto H, Schuster G, Schwarz JP, Seland Ø, Stier P, Takegawa N, Takemura T, Textor C, van Aardenne JA, Zhao Y (2009) Evaluation of black carbon estimations in global aerosol models. Atmos Chem Phys 9:9001-9026

Kurokawa J, Ohara T, Morikawa T, Hanayama S, Greet JM, Fukui T, Kawashima K, Akimoto H (2013) Emissions of air pollutants and greenhouse gases over Asian regions during 2000-2008: regional emission inventory in ASia (REAS) version 2. Atmos Chem Phys 13:11019-11058

Kurokawa J, Yumimoto K, Itahashi S, Nagashima T, Maki T, Ohara T (2017) Evaluation of historical emission inventory in Asia. 18th GEIA conference, Hamburg

Masutomi Y, Ono K, Mano M, Maruyama A, Miyata A (2016a) A land surface model combined with a crop growth model for paddy rice (MATCRO-Rice Ver. 1)-part I: model description. Geosci Model Dev 9:4133-4154

Masutomi Y, Ono K, Takimoto T, Mano M, Maruyama A, Miyata A (2016b) A land surface model combined with a crop growth model for paddy rice (MATC RO-Rice Ver. 1)-part II: model validation. Geosci Model Dev 9:4155-4167

Matsui H, Hamilton DS, Mahowald NM (2018) Black carbon radiative effects highly sensitive to emitted particle size when resolving mixing-state diversity. Nature Comm 9:3446. https://doi.org/10.1038/s41467-018-05635-1

Meinshausen M, Raper SCB, Wigley TML (2011) Emulating coupled atmosphereocean and carbon cycle models with a simpler model, MAGICC6: part I model description and calibration. Atmos Chem Phys 11:1417-1456. https:// doi.org/10.5194/acp-11-1417-2011

Michibata T, Suzuki K, Sato Y, Takemura T (2016) The source of discrepancies in aerosol-cloud-precipitation interactions between GCM and A-train retrievals. Atmos Chem Phys 16:15413-15424. https://doi.org/10.5194/acp-16-15413-2016

Mills G, Sharps K, Simpson D, Pleijel H, Frei M, Burkey K, Emberson L, Uddling J, Broberg M, Feng Z, Kobayashi K, Agrawal M (2018) Closing the global ozone yield gap: quantification and cobenefits for multistress tolerance. Glob Chang Biol 24:4869-4893. https://doi.org/10.1111/gcb.14381

Moteki N, Adachi K, Ohata S, Yoshida A, Harigaya T, Koike M, Kondo Y (2017) Anthropogenic iron oxide aerosols enhance atmospheric heating. Nat Commun 8:15329

Myhre G, Forster PM, Samset BH, Hodnebrog Ø, Sillmann J, Aalbergsjø SG, Andrews T, Boucher O, Faluvegi G, Fläschner D, Iversen T, Kasoar M, Kharin V, Kirkevag A, Lamarque JF, Olivié D, Richardson TB, Shindell D, Shine KP, Stjern CW, Takemura T, Voulgarakis A, Zwiers F (2017) PDRMIP: a precipitation driver and response model Intercomparison project-protocol and preliminary results. Bull Am Meteorol Soc 98(6):1185-1198. https://doi.org/10.1175/BAMS-D-16-0019.1

Myhre G, Samset BH, Schulz M, Balkanski Y, Bauer S, Berntsen TK, Bian H, Bellouin N, Chin M, Diehl T, Easter RC, Feichter J, Ghan SJ, Hauglustaine D, Iversen T,
Kinne S, Kirkevåg A, Lamarque JF, Lin G, Liu X, Lund MT, Luo G, Ma X, van Noije T, Penner JE, Rasch PJ, Ruiz A, Seland $\varnothing$, Skeie RB, Stier P, Takemura T, Tsigaridis K, Wang P, Xu L, Yu H, Yu F, Yoon JH, Zhang K, Zhang H, Zhou C (2013) Radiative forcing of the direct aerosol effect from AeroCom phase II simulations. Atmos Chem Phys 13:1853-1877

Nakajima T, Yoon SC, Ramanathan V, Shi GY, Takemura T, Higurashi A, Takamura T, Aoki K, Sohn BJ, Kim SW, Tsuruta H, Sugimoto N, Shimizu A, Tanimoto H, Sawa Y, Lin NH, Lee CT, Goto D, Schutgens N (2007) Overview of the atmospheric Brown cloud east Asian regional experiment 2005 and a study of the aerosol direct radiative forcing in East Asia. J Geophys Res 112:D24S91. https://doi.org/10.1029/2007JD009009

O'Neill BC, Kriegler E, Ebi KL, Kemp-Benedict E, Riahi K, Rothman DS, van Ruijven BJ, van Vuuren DP, Birkmann J, Kok K, Levy M, Solecki W (2015) The roads ahead: narratives for shared socioeconomic pathways describing world futures in the 21st century. Glob Environ Chang. https://doi.org/10.1016/j. gloenvcha.2015.01.004

Oshima N, Koike M (2013) Developmeent of a parameterization of black carbon aging for use in general circulation models. Geosci Model Dev 6:263-282

Ramanathan V, Crutzen PJ (2003) New directions: atmospheric brown clouds. Atmos Environ 37:4033-4035

Samset BH, Myhre G, Forster PM, Hodnebrog Ø, Andrews T, Faluvegi G, Fläschner D, Kasoar M, Kharin V, Kirkevåg A, Lamarque JF, Olivié D, Richardson T, Shindell D, Shine KP, Takemura T, Voulgarakis A (2016) Fast and slow precipitation responses to individual climate forcers: a PDRMIP multimodel study. Geophys Res Lett 43:2782-2791. https://doi.org/10.1002/2016GL068064

Sato Y, Goto D, Michibata T, Suzuki K, Takemura T, Tomita H, Nakajima T (2018) Aerosol effects on cloud water amounts were successfully simulated by a global cloud-system resolving model. Nat Commun 9:985. https://doi.org/10. 1038/s41467-018-03379-6

Sato Y, Miura H, Yashiro H, Goto D, Takemura T, Tomita H, Nakajima T (2016) Unrealistically pristine air in the Arctic produced by current global scale models. Sci Rep 6:26561

Sato Y, Suzuki K (2019) How do aerosols affect cloudiness? Science 363:580-581. https://doi.org/10.1126/science.aaw3720

Schulz M, Textor C, Kinne S, Balkanski Y, Bauer S, Berntsen T, Berglen T, Boucher $\mathrm{O}$, Dentener F, Guibert S, Isaksen ISA, Iversen T, Koch D, Kirkevåg A, Liu X, Montanaro V, Myhre G, Penner JE, Pitari G, Reddy S, Seland $\varnothing$, Stier P, Takemura $\mathrm{T}$ (2006) Radiative forcing by aerosols as derived from the AeroCom present-day and pre-industrial simulations. Atmos Chem Phys 6:5225-5246

Seposo X, Ueda K, Park SS, Sudo K, Takemura T, Nakajima T (2019) Effect of global atmospheric aerosol emission change on PM2.5-related health impacts. Glob Health Action 12:1664130. https://doi.org/10.1080/16549716.2019.1664130

Shindell DT, Faluvegi G, Koch DM, Schmidt GA, Unger N, Bauer SE (2009) Improved attribution of climate forcing to emissions. Science 326:716-718. https://doi.org/10.1126/science.1174760

Shindell DT, Lamarque JF, Schulz M, Flanner M, Jiao C, Chin M, Young PJ, Lee YH, Rotstayn L, Mahowald N, Milly G, Faluvegi G, Balkanski Y, Collins WJ, Conley AJ, Dalsoren S, Easter R, Ghan S, Horowitz L, Liu X, Myhre G, Nagashima T, Naik V, Rumbold ST, Skeie R, Sudo K, Szopa S, Takemura T, Voulgarakis A, Yoon JH, Lo F (2013) Radiative forcing in the ACCMIP historical and future climate simulations. Atmos Chem Phys 13:2939-2974

Shrivastava M, Cappa CD, Fan J, Goldstein AH, Guenther AB, Jimenez JL, Kuang C, Laskin A, Martin ST, Ng NL, Petaja T, Pierce JR, Rasch PJ, Roldin P, Seinfeld JH, Shilling J, Smith JN, Thornton JA, Volkamer R, Wang J, Worsnop DR, Zaveri RA, Zelenyuk A, Zhang Q (2017) Recent advances in understanding secondary organic aerosol: implications for global climate forcing. Rev Geophys 55:509-559. https://doi.org/10.1002/2016RG000540

Smith CJ, Kramer RJ, Myhre G, Forster PM, Soden BJ, Andrews T, Boucher O, Faluvegi G, Fläschner D, Hodnebrog $\varnothing$, Kasoar M, Kharin V, Kirkevåg A, Lamarque JF, Mülmenstädt J, Olivié D, Richardson T, Samset BH, Shindell D, Stier P, Takemura T, Voulgarakis A, Watson-Parris D (2018) Understanding rapid adjustments to diverse forcing agents. Geophys Res Lett 45:1202312031. https://doi.org/10.1029/2018GL079826

Stjern CW, Samset B, Myhre G, Forster PM, Hodnebrog Ø, Andrews T, Bucher O, Faluvegi G, Iversen T, Kasoar M, Kharin V, Kirkevåg A, Lamarque JF, Olivié D, Richardson T, Shawki D, Shindell D, Smith CJ, Takemura T, Voulgarakis A (2017) Rapid adjustments cause weak surface temperature response to increased black carbon concentrations. J Geophys Res Atmos 122:1146211481. https://doi.org/10.1002/2017JD027326

Stjern CW, Samset BH, Myhre G, Bian H, Chin M, Davila Y, Dentener F, Emmons L, Flemming J, Haslerud AS, Henze D, Jonson JE, Kucsera T, Lund MT, Schulz M, 
Sudo K, Takemura T, Tilmes S (2016) Global and regional radiative forcing from 20\% reductions in BC, OC and SO4 - an HTAP2 multi-model study. Atmos Chem Phys 16:13579-13599. https://doi.org/10.5194/acp-16-13579-2016 Stohl A, Aamaas B, Amann M, Baker LH, Bellouin N, Berntsen TK, Boucher O, Cherian R, Collins W, Daskalakis N, Dusinska M, Eckhardt S, Fuglestvedt JS, Harju M, Heyes C, Hodnebrog Ø, Hao J, Im U, Kanakidou M, Klimont Z, Kupiainen K, Law KS, Lund MT, Maas R, MacIntosh CR, Myhre G, Myriokefalitakis S, Olivié D, Quaas J, Quennehen B, Raut JC, Rumbold ST, Samset BH, Schulz M, Seland Ø, Shine KP, Skeie RB, Wang S, Yttri KE, Zhu T (2015) Evaluating the climate and air quality impacts of short-lived pollutants. Atmos Chem Phys 15:10529-10566

Sudo K, Akimoto H (2007) Global source attribution of tropospheric ozone: longrange transport from various source regions. J Geophys Res 112. https://doi. org/10.1029/2006JD007992

Suzuki K, Takemura T (2019) Perturbations to global energy budget due to absorbing and scattering aerosols. J Geophys Res 124:2194-2209. https://doi. org/10.1029/2018JD029808

Takahashi HG, Watanabe S, Nakata M, Takemura T (2018) Response of the atmospheric hydrological cycle over the tropical Asian monsoon regions to anthropogenic aerosols and its seasonality. Prog Earth Planet Sci 5(44). https://doi.org/10.1186/s40645-018-0197-2

Takemura T, Nozawa T, Emori S, Nakajima TY, Nakajima T (2005) Simulation of climate response to aerosol direct and indirect effects with aerosol transportradiation model. J Geophys Res 110:D02202. https://doi.org/10.1029/ 2004JD005029

Takemura T, Suzuki K (2019) Weak global warming mitigation by reducing black carbon emissions. Sci Rep 9:4419

Tatebe H, Ogura T, Nitta T, Komuro Y, Ogochi K, Takemura T, Sudo K, Sekiguchi M, Abe M, Saito F, Chikira M, Watanabe S, Mori M, Hirota N, Kawatani Y, Mochizuki T, Yoshimura K, Takata K, O'ishi R, Yamazaki D, Suzuki T, Kurogi M, Kataoka T, Watanabe M, Kimoto M (2019) Description and basic evaluation of simulated mean state, internal variability, and climate sensitivity in MIROC6. Geosci Model Dev 12:2727-2765. https://doi.org/10.5194/gmd-12-2727-2019

Tomita H, Satoh M (2004) A new dynamical framework of nonhydrostatic global model using the icosahedral grid. Fluid Dyn Res 34:357

UNEP (2018) Air pollution in Asia and the Pacific: science-based solutions UNEP ISBN: 978-92-807-3725-7

UNEP and WMO (2011) Integrated assessment of black carbon and tropospheric ozone: summary for decision makers UNEP, ISBN: 978-92-807-3142-2

Watanabe M, Suzuki T, O'ishi R, Komuro Y, Watanabe S, Emori S, Takemura T, Chikira M, Ogura T, Sekiguchi M, Takata K, Yamazaki D, Yokohata T, Nozawa T, Hasumi H, Tatebe H, Kimoto M (2010) Improved climate simulation by MIROC5: mean states, variability, and climate sensitivity. J Climate 23:6312-6335

Yoshimura K, Nitta T, Ishizuka Y, Tada M, Suzuki K, Takemura T (2018) Effects of short-lived climate pollutants to the land area water circulation. J Japan Soc Civil Eng Ser B1 Hydra Eng 74(4):I_217-I_222 in Japanese

Yumimoto K, Uno I, Itabashi S, Kuribayashi M, Miyazaki K (2015) Application of inversion technique to quick update of anthropogenic $\mathrm{NO}_{x}$ emission with satellite observations and chemical transport model. J Jpn Soc Atmos Environ 50(5):199-206 in Japanese

Zhao S, Suzuki K (2019) Differing impacts of black carbon and sulfate aerosols on global precipitation and the ITCZ location via atmosphere and ocean energy perturbations. J Climate 32:5567-5582. https://doi.org/10.1210/JCLI-D-180616.1

\section{Publisher's Note}

Springer Nature remains neutral with regard to jurisdictional claims in published maps and institutional affiliations.

\section{Submit your manuscript to a SpringerOpen ${ }^{\circ}$ journal and benefit from:}

- Convenient online submission

- Rigorous peer review

- Open access: articles freely available online

- High visibility within the field

- Retaining the copyright to your article

Submit your next manuscript at $\boldsymbol{\nabla}$ springeropen.com 